\title{
IN-SITU, LONG-TERM MONITORING SYSTEM FOR RADIOACTIVE CONTAMINANTS
}

\author{
Final Technical Report \\ Reporting Period Start Date: September 27, 2001 \\ Reporting Period End Date: December 27, 2002 \\ Authors: James S. Durham, Stephen W. S. McKeever, Mark S. Akselrod \\ Report Issue Date: October 2002 \\ DOE Award Number: DE-AC26-01NT41300 \\ Prepared by: Department of Radiological Health Sciences \\ Colorado State University \\ Fort Collins, CO 80523 \\ Department of Physics \\ Oklahoma State University \\ Stillwater, OK 74078 \\ Landauer Stillwater Crystal Growth Division \\ $723 \frac{1}{2}$ Eastgate \\ Stillwater, OK 74074 \\ Prepared for: U.S. Department of Energy \\ National Energy Technology Laboratory \\ 3610 Collins Ferry Road \\ Morgantown, WV 26505 \\ COR: Ron K. Staubly
}

\footnotetext{
This report was prepared as an account of work sponsored by an agency of the United States Government. Neither the United States Government nor any agency thereof, nor any of their employees, makes any warranty, express or implied, or assumes any legal liability or responsibility for the accuracy, completeness, or usefulness of any information, apparatus, product, or process disclosed, or represents that its use would not infringe privately owned rights. Reference herein to any specific commercial product, process, or service by trade name, trademark, manufacturer, or otherwise does not necessarily constitute or imply its endorsement, recommendation, or favoring by the United States Government or any agency thereof. The views and opinions of authors expressed herein do not necessarily state or reflect those of the United States Government or any agency thereof.
} 


\begin{abstract}
This report presents the results of the first phase of the project entitled "In-situ, Long-term Monitoring System for Radioactive Contaminants." Phase one of this effort included four objectives, each with specific success criteria.

The first objective was to produce dosimetry grade fibers and rods of aluminum oxide. The success criterion for this milestone was the production of aluminum oxide rods and fibers that have a minimum measureable dose (MMD) of 100 mrem or less. This milestone was completed and the MMD for the rods was measured to be 1.53 mrem. Based on the MMD, the ability of the sensor to measure ${ }^{137} \mathrm{Cs},{ }^{90} \mathrm{Sr} /{ }^{90} \mathrm{Y}$, and ${ }^{99} \mathrm{Tc}$ was evaluated. It was determined that the sensor can measure the release limit of these radionuclides $\left(50 \mathrm{pCi} / \mathrm{cm}^{3}\right)$ in $150 \mathrm{~h}, 200 \mathrm{~h}$, and $54,000 \mathrm{~h}$, respectively. The monitor is adequate for measuring ${ }^{137} \mathrm{Cs}$ and ${ }^{90} \mathrm{Sr} /{ }^{90} \mathrm{Y}$ but is unsuitable for measuring ${ }^{99} \mathrm{Tc}$ in soil.
\end{abstract}

The second objective was to construct a prototype sensor (dosimeter and fiber optic channel). There were three success criteria for this milestone: 1) Perform measurements with the sensor for both gamma and beta radiation with a standard deviation of $10 \%$ or less; 2) Demonstrate the ability of the sensor to discriminate between gamma and beta radiation; and 3) Obtain similar or relatable results for differing lengths of fiber optic cable. These milestones were met. The sensor was able to measure gamma radiation repeatedly with a standard deviation of $3.15 \%$ and beta radiation with a standard deviation of $2.85 \%$. Data is presented that demonstrates that an end cap can be used to discriminate between beta plus gamma and gamma radiation. It is shown that some amount of attenuation occurs in longer fiber optic cables, but it is unclear if the attenuation is due to poor alignment of the dosimeter and the cable. This issue will be investigated further when more dosimeters are available so that the dosimeters can be permanently attached to the longer cables.

The third objective was to identify a demonstration site. The success criterion for this milestone was to obtain a written agreement from a DOE site to host the demonstration of the monitor during the third phase. Because of uncertainties in funding of the second and third phases of this effort, a written agreement was not obtained. Instead, verbal agreements were reached with both Hanford and the Nevada Test Site. It is believed that the verbal agreements meet the intent of the objective.

The final objective was to prepare the Draft Phase I Topical Report. The success criterion for this milestone was to have the report accepted by NETL. It is anticipated that this objective will be met. 


\title{
TABLE OF CONTENTS
}

\author{
ABSTRACT \\ FIGURES \\ TABLES \\ 1. EXECUTIVE SUMMARY \\ 1.1 Scope of Work \\ 1.2 Project Objectives and Success Criteria \\ 1.2.1 Dosimeter Production \\ 1.2.2 Prototype Sensor Construction and Testing \\ 1.2.3 Identify Demonstration Site \\ 1.2.4 Prepare Draft Phase I Topical Report \\ 2. BACKGROUND \\ 2.1 Benefits of the Monitor to the User \\ 2.2 Technology Development Requirements \\ 2.3 Description of the Technology \\ 3. RESULTS AND DISCUSSION \\ 3.1 Dosimeter Production \\ 3.2 Monitor Construction and Testing \\ 3.2.1 Sensor Construction and Testing \\ 3.2.2 Reader Construction and Testing \\ 3.2.2.1 Measurement Repeatability \\ 3.2.2.2 Discrimination between Beta and Gamma Radiation \\ 3.2.2.3 Tests on Different Lengths of Fiber Optic Cable \\ 4. CONCLUSIONS \\ 5. FUTURE WORK \\ 6. REFERENCES
}




\section{FIGURES}

1. Crystal Growth Furnace Used for Pulling Single Crystal Fibers

2. Schematic Diagram of the Fiber Pulling Process and Shaping Unit Designs Used in the Production of Single Crystal $\mathrm{Al}_{2} \mathrm{O}_{3}: \mathrm{C}$ Fibers of Two Different Diameters

3. Uncut Radiation Sensitive $\mathrm{Al}_{2} \mathrm{O}_{3}: \mathrm{C}$ Fibers

4. Cut and Polished Radiation Sensitive $\mathrm{Al}_{2} \mathrm{O}_{3}: \mathrm{C}$ Fibers

5. Dosimeter and Fiber Optic Cable Alignment Equipment

6. Data Used to Determine the Minimum Detectable Dose for the Sensor

7. $\quad{ }^{137} \mathrm{Cs}$ Concentration as a Function of Exposure Time

8. $\quad{ }^{90} \mathrm{Y}$ Concentration as a Function of Exposure Time

9. Schematic Diagram of the Portable Reader

10. The OSL Reader System, Including the Reader (Background), the Red Fiber Optic Channel, the Irradiation/Readout Chamber, and a Laptop Computer for Data Acquisition

11. Interior of OSL Reader Showing the Silver Laser, the Black PMT, the Half-Silvered Mirror (between Laser and PMT), and the Laser Power Supply

12. Unlighted Sensor Showing Interface between the $\mathrm{Al}_{2} \mathrm{O}_{3}$ Fiber and the Silica Fiber Optic Channel

13. Stimulated Sensor Showing Light Scatter at the Fiber/Fiber Optic Interface

14. Results of Gamma Dose Repeatability Measurements

15. Results of the Beta Dose Repeatability Measurements. The OSL Signal Has Been Corrected for Background

16. Schematic Diagram of the Fiber Probe with End Cap

17. Beta Shield End Cap Alone and in Place

18. Multiple Radioluminescence Readings for a Four-Second Beta Irradiation without the End Cap

19. Single Radioluminescence Reading for a Four-Second Beta Irradiation the End Cap in Place

20. Results of Irradiation of Fiber with End cap by Gamma and Beta Radiation. The End Cap Effectively Shields the Beta Radiation. Inset: Results of Irradiation by Gamma Radiation with and without End Cap in Place. There Is No Significant Difference Between Responses to Gamma Radiation

21. Pulsed Laser and Power Supply to be Incorporated into a Portable Reader 


\section{TABLES}

1. Minimum Detectable Dose for three different growths of $\mathrm{Al}_{2} \mathrm{O}_{3}$ fibers

2. Detectable Level of Contamination after a 24 hour Exposure

3. OSL Signal as a Function of Fiber Optic Cable Length 


\section{EXECUTIVE SUMMARY}

Under contract DE-AC26-01NT41300, a collaborative effort led by Colorado State University has completed the first phase of a planned three-phase effort to develop an in-situ, long-term monitor for radioactive contaminants at DOE remediation sites. Progress toward the development was excellent and some of the goals originally scheduled to be completed during the first option year of the effort were completed during the first phase. Development of the monitor has consistently progressed according to the schedule provided in the management plan.

\section{1_ Scope of Work}

The objective of this project is to develop and demonstrate a low-cost, long-term in situ subsurface monitoring system for radioactive contaminant plumes. The system consists of a sensor based on optically-stimulated luminescence (OSL) readout of $\alpha-\mathrm{Al}_{2} \mathrm{O}_{3}: \mathrm{C}$ (aluminum oxide) rods and a reader that interrogates the sensor at a prescribed frequency. Within a period of three years, this project will demonstrate, on a prototypical scale at a Department of Energy (DOE) site, a monitoring system that is capable of providing essentially real time measurements of the presence or absence of underground radioactive contaminant plumes.

The monitor will replace the need for repeated soil sampling around waste tanks, trenches, pits, cribs, and other sources or potential sources of gamma- or beta-emitting radioactive material. The monitor will also provide the Department of Energy (DOE) with a low-cost method of verifying, on a continuous basis, the absence of radioactive contaminant plumes and detecting changes in the activity of known contaminant plumes. The monitor will detect an increase in radioactivity at a given location or array of locations, thus providing a detection system for long term monitoring of waste tanks and trenches.

The monitor consists of a sensor and a readout device. The sensor consists of a short $(\sim 1 \mathrm{~cm})$ aluminum oxide rod that is physically and optically coupled to a conventional fiber optic channel. The sensor is placed in new or existing boreholes around radioactive waste sources such as waste tanks, trenches, and cribs. The fiber optic channels are sheathed in an inert material to prevent damage to the channel and to facilitate deployment in potentially hazardous environments. Aluminum oxide is an inert, structurally strong material that will not interact or be affected by hazardous materials that it may contact during deployment. A portable readout device, consisting of a light source, a photomultiplier tube, and associated electronics, will be used to measure radiation dose collected by the sensor. The measured dose is subsequently correlated to the type of radioactive contaminants and contamination levels in the soil by using appropriate calibration factors.

The scope of the first phase of this effort is to build and test the sensor portion of the monitor. The planned work is to construct the sensor and perform bench top testing using a high-powered laser as 
the readout light source. This will allow measurement in a "best case" scenario. The results of the work were excellent and a portable reader was constructed, allowing preliminary bench top testing of the monitor (sensor and reader) to be completed. These latter measurements were originally scheduled for completion during the second phase of the project.

Phase one of this effort is divided into three tasks and involves three entities: Colorado State University (CSU), Landauer Crystal Growth Division (Landauer), and Oklahoma State University (OSU). The Landauer Stillwater Crystal Growth Facility produces dosimetry-grade aluminum oxide single crystals and powders for commercial applications. The most notable application is the use of aluminum oxide powder in the Landauer, Inc. personnel dosimetry system marketed under the trade name Luxel. Oklahoma State University holds several patents for the use of aluminum oxide and Landauer is licensed to use the technology. The license will greatly facilitate the technology transfer process. The principal investigator at Landauer is Mark Akselrod. The Optically and Thermally Stimulated Phenomena Laboratory at OSU specializes in developing dosimeter applications for solid state dosimeters, including aluminum oxide. The principal investigator at OSU is Steve McKeever.

In phase one of this project, Landauer will produce the aluminum oxide dosimeters in the form of rods and fibers. OSU will couple the dosimeter to the fiber-optic channel to make the sensor and perform bench top experiments to determine the sensitivity of the sensor. After performing the experiments, OSU will provide Landauer with technical requirements and suggested improvements to the dosimeter, and Landauer will produce new dosimeters that reflect these needs, if necessary. CSU will provide project management, integrate the efforts of Landauer and OSU, and begin planning for the phase three demonstration.

\subsection{Project Objectives and Success Criteria}

Phase one of this effort included four objectives, each with specific success criteria. This section presents and discusses each objective.

\subsubsection{Dosimeter Production}

The first objective was to produce dosimetry grade fibers and rods of aluminum oxide. The success criterion for this milestone was the production of aluminum oxide rods and fibers that have a minimum detectable activity (MDA) of 100 mrem or less. This milestone was completed, and the MDA for the rods was determined to be less that $2 \mathrm{mrem}$. The responsible entity for this objective was Landauer.

\subsubsection{Prototype Sensor Construction and Testing}

The second objective was to construct a prototype sensor (dosimeter and fiber optic channel). There were three success criteria for this milestone: 1) Perform measurements with the sensor for both 
gamma and beta radiation with a standard deviation of $10 \%$ or less; 2) Obtain similar or relatable results for differing lengths of fiber optic cable; and 3) Demonstrate the ability of the sensor to discriminate between gamma and beta radiation. These milestones were met. The responsible entity for this objective was OSU.

\subsubsection{Identify Demonstration Site}

The third objective was to identify a demonstration site. The success criterion for this milestone was to obtain a written agreement from a DOE site to host the demonstration of the monitor during the third phase. Because of anticipated uncertainties in funding of the second and third phases of this effort, a written agreement was not obtained. Instead, verbal agreements were reached with both Hanford and the Nevada Test Site.

\subsubsection{Prepare Draft Phase I Topical Report}

The final objective was to prepare the Draft Phase I Topical Report. The success criterion for this milestone was to have the report accepted by NETL. It is anticipated that this objective will be met.

\section{BACKGROUND}

Characterization and monitoring of waste tanks, trenches, and cribs is an essential ingredient in the surveillance of radioactive waste at DOE sites, both during the remediation process and after remediation is complete. Subsurface monitoring must be performed at different depths in the ground, at different distances from potential and actual sources, and in all directions from potential and actual sources. At the Hanford Site alone, 177 high-level waste tanks store highly radioactive waste in liquid form. Many of these tanks are single-shell steel vessels that are already leaking. Monitoring of the remediation of these tanks is necessary to demonstrate the effectiveness of the effort to remove or contain the radioactive contaminants. Because of its long operating history, Hanford contains a large assortment of waste sources, including buried train cars, unlined waste cribs used to contain highly radioactive waste from the plutonium-uranium extraction process, and radioactive trenches with known leakage. It is crucial that migration of waste from these sources be detected promptly during the remediation process. Once remediation is complete, long term automated, unattended verification of the effectiveness of remediation is needed. Finally, verification of no-further-action decisions must be provided.

\subsection{Benefits of the Monitor to the User}

The greatest benefit of the subsurface monitor is to provide long-term monitoring of waste plumes or areas where radioactive waste plumes may develop. The sensor is rugged and will be designed to monitor the presence or absence of radioactive waste in groundwater, sediments, soil, and 
engineered units. It is expected that the sensor portion of the subsurface monitor will cost less than $\$ 50$ each and will provide data for many years.

This technology can be applied at any DOE site that has waste streams that contain gamma and medium- to high-energy beta sources including ${ }^{137} \mathrm{Cs},{ }^{90} \mathrm{Sr} /{ }^{90} \mathrm{Y}$, and potentially ${ }^{99} \mathrm{Tc}$. Typical sites that would benefit from this technology include the Savannah River Site, Los Alamos National Laboratory, Idaho National Environmental Engineering Laboratory, the Hanford Site, the Nevada Test Site, and Oak Ridge National Laboratory.

Successful completion of this project will result in a tool that has benefit to all DOE sites that require remediation, including those sites that will require long-term automated monitoring with data archiving. The subsurface monitor is simple to use after installation and should require little maintenance. The subsurface monitor is suitable for monitoring known radioactive underground plumes, for verifying that underground plumes do not exist, and for detecting and characterizing plumes. Information on the size and concentration of the radioactive plumes can also be determined from the data gathered by the subsurface monitor. The use of the subsurface monitor represents a considerable cost savings over currently available technology and methods. Transfer of the technology to Landauer, Inc. will ensure that implementation of the subsurface monitor throughout the DOE complex can be realized.

\subsection{Technology Development Requirements}

The current method for monitoring and characterizing radioactive contaminant plumes is to drill boreholes and remove samples from the plume region. This method is expensive, time consuming, and requires the samples to be taken to a laboratory for analysis. Further, this method requires disposal of the radioactive samples. Once the first sample is removed from a borehole, subsequent samples taken from the same borehole, if they are needed, may not be representative of the actual soil and/or water conditions in the vicinity, and continued monitoring can be difficult. Current plans are to obtain soil samples at a frequency of 1 to four samples per year per location.

In order for the subsurface monitor to be successful, the monitor must be able to measure radioactive soil contamination levels at the release level within a time period of less than three months. This can be achieved if the MDA of the sensor is sufficiently low enough to measure the accumulated dose from contamination at the release level during a three-month exposure period. It must also be able to distinguish between gamma radiation from ${ }^{137} \mathrm{Cs}$ and beta radiation from ${ }^{90} \mathrm{Sr} /{ }^{90} \mathrm{Y}$. 


\subsection{Description of the Technology}

The subsurface monitor consists of a relatively inexpensive passive sensor and a readout device. The sensors are made from a hypersensitive dosimeter material, aluminum oxide, that was originally developed for its thermoluminescent (TL) properties. Aluminum oxide is one of the most sensitive solid state dosimeter materials ever developed. It is capable of measuring doses as low as 10's of $\mu \mathrm{rad}$, or about 1 to 2 hours of natural background radiation. Integrated doses as high as $1 \mathrm{krad}$ can be measured before nonlinearities begin to occur in the response. However, for this application in which the dosimeter is interrogated frequently, it is not anticipated that doses of this magnitude will be encountered. When used in a dark environment, the signal collected by the sensor does not fade over a period of 2 years or more. The chemical and physical stability of the sensor is of particular importance in this application. Landauer, Inc. produces aluminum oxide at the Stillwater Crystal Growth Facility in Stillwater, Oklahoma. Although developed for use as a thermoluminescent dosimeter (TLD) ${ }^{1}$ and an exoelectron dosimeter, ${ }^{2}$ its greatest commercial success has come from the exploitation of its Optically Stimulated Luminescence (OSL) properties. ${ }^{3,4}$ The subsurface monitor is based on an aluminum oxide fiber, a chemically inert and physically stable material that is sometimes referenced as sapphire. ${ }^{5}$ It is expected that the sensor will not raise any environmental or regulatory concerns because of the inertness of the material and its small volume. Once installed, the subsurface monitor will not require that contaminated or potentially contaminated soil be disturbed or removed.

Thermoluminescent dosimeters are insulator crystals that are able to trap and store electrons that are formed when radiation interacts with the crystal. Electrons in these traps, which are stable at room temperature, are emptied when the TLD is heated. When the electrons are released, they lose their stimulation energy by emitting visible light. The amount of light released when the TLD is heated is proportional to the dose absorbed by the TLD. Heating temperatures of up to $500^{\circ} \mathrm{C}$ are often required when using the TL process. ${ }^{6}$ In OSL, the traps are released by stimulating the crystal with certain wavelengths of light. In aluminum oxide, the stimulation wavelength is between 500 - 535 $\mathrm{nm}$ (green light) and the wavelength of the emitted light is around $420 \mathrm{~nm}$ (blue light). ${ }^{3}$ Because of the difference between the stimulation wavelength and the emission wavelength, it is possible to stimulate the crystal and collect the emitted light simultaneously. Once the electrons are removed from the traps, the sensor is "reset" to zero (a process called "bleaching") and another measurement is started. The sensor can be completely bleached using only the stimulating wavelength or the signal could be allowed to remain. This would allow the previous information to be read multiple times.

Readout is performed by optically stimulating the sensor, a very reliable technique that does not require heating of the sensor. The reader consists of a light source, a photomultiplier tube, and associated data acquisition hardware. The choice of a laser as a light source was made as part of this project. A laser requires only a broadband filter and, therefore, higher sensitivity is realized. Additional considerations were given to the mode of stimulation, that is whether or not the probe 
will be addressed with constant intensity light source (CW mode), or with a pulsed source (pulsed mode). Results obtained to date are from $\mathrm{CW}$ stimulation, although the capability for pulsed stimulation exists and future phases of this effort will include pulsed stimulation methods.

\section{RESULTS AND DISCUSSION}

This section will discuss the results of this effort in three areas: dosimeter growth, sensor design and testing, and monitor demonstration siting. Some of the information in this section is proprietary and is not intended for general release. This information will be marked in accordance with the contractual agreement.

\subsection{Dosimeter Production}

The information given in this section is proprietary and is the property of Landauer Inc.

A feasibility study was performed prior to this contract in order to demonstrate that Landauer's proprietary crystal growth technique allows one to obtain $\alpha-\mathrm{Al}_{2} \mathrm{O}_{3}: \mathrm{C}$ single crystal fibers suitable for environmental dosimetry applications. The biggest challenge was to demonstrate the ability to grow $\mathrm{Al}_{2} \mathrm{O}_{3}$ single crystal fibers of different diameters and with the properties desired for a very low dose rates and low environmental radionuclide activities.

Crystal growth of $\mathrm{Al}_{2} \mathrm{O}_{3}$ : C fibers was performed in a water cooled double wall stainless steel vessel of an induction heating furnace (Figure 1) in a highly reducing atmosphere and at low partial pressure of oxygen $\left(\sim 10^{-20} \mathrm{~atm}\right)$. These conditions stimulate the creation of oxygen vacancies in the $\mathrm{Al}_{2} \mathrm{O}_{3}$ crystal structure and were obtained using an argon atmosphere and a hot graphite succeptor coupled to the water-cooled inductor of an induction-heating furnace. Crystal growth was performed at $2050{ }^{\circ} \mathrm{C}$ with pulling rate in the range of 0.5 to $10 \mathrm{~mm} / \mathrm{min}$.

Several designs and configurations of the crystal growth assembly were tested. For this project, two configurations of a shaping unit based on molybdenum tubing was proposed and tested to pull single crystal fibers from the melt (Figure 2). The surface tension of the aluminum oxide melt and the wetting properties of molybdenum were used to form a crystal with a diameter less than the diameter of the shaping unit, which is made of thin-walled molybdenum tubing. The crystalline fibers of three diameters $<500 \mu \mathrm{m}, 1000 \mu \mathrm{m}$, and $2000 \mu \mathrm{m}$ were obtained (Figure 3). The crystals were than cut into lengths of $3 \mathrm{~mm}, 6 \mathrm{~mm}$, and $9 \mathrm{~mm}$. The fibers were polished on both ends to obtain optical quality surfaces for coupling with silica fiber-optic cables (Figure 4) and were used in a prototype POSL reader design. Figure 4 shows the fibers after cutting and polishing. 


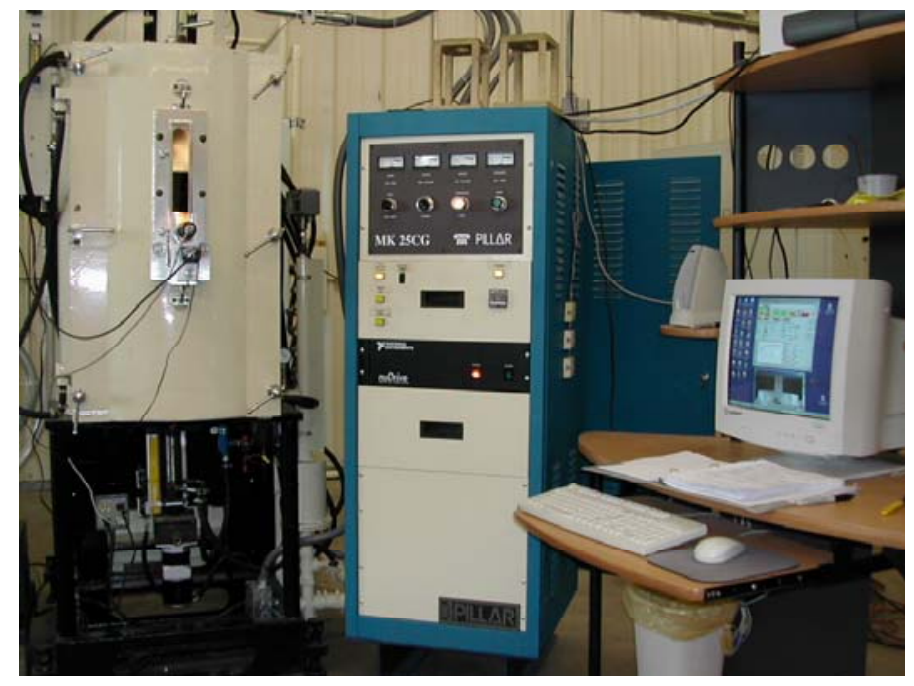

Figure 1 Crystal Growth Furnace Used for Pulling Fibers

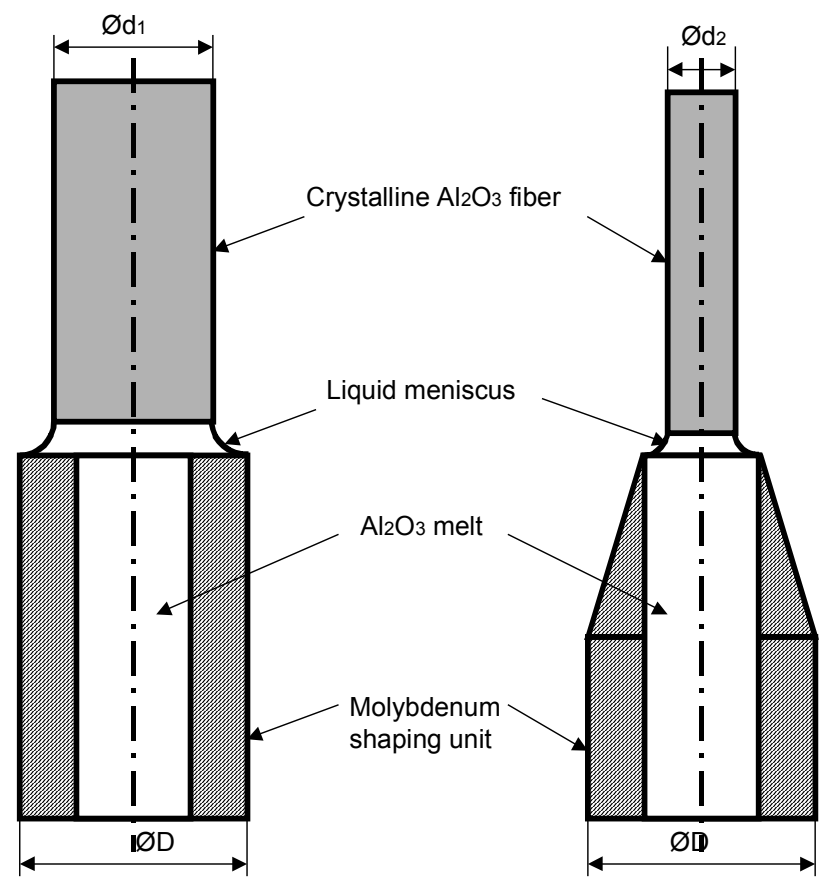

(a)

(b)

Figure 2. Schematic Diagram of the Fiber Pulling Process and Shaping Designs Used in the Production of Single Crystal $\mathrm{Al}_{2} \mathrm{O}_{3}: \mathrm{C}$ Fibers of Two Different Diameters 


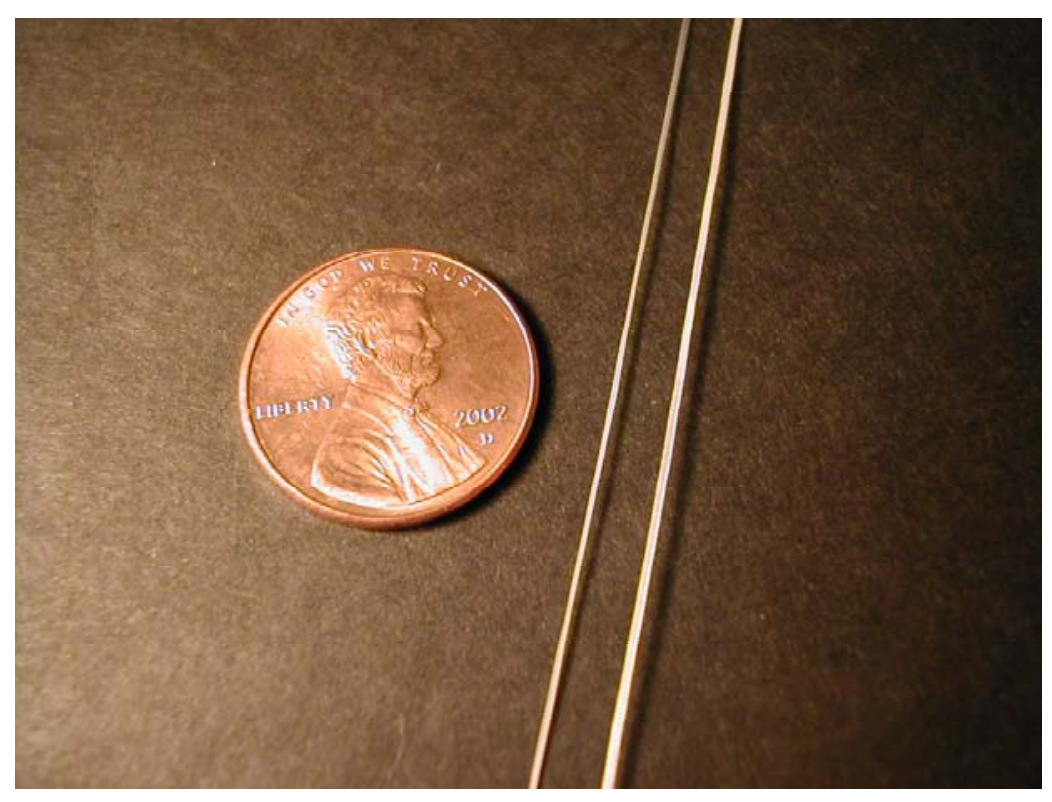

Figure 3. Uncut Radiation Sensitive $\mathrm{Al}_{2} \mathrm{O}_{3}:$ C Fibers

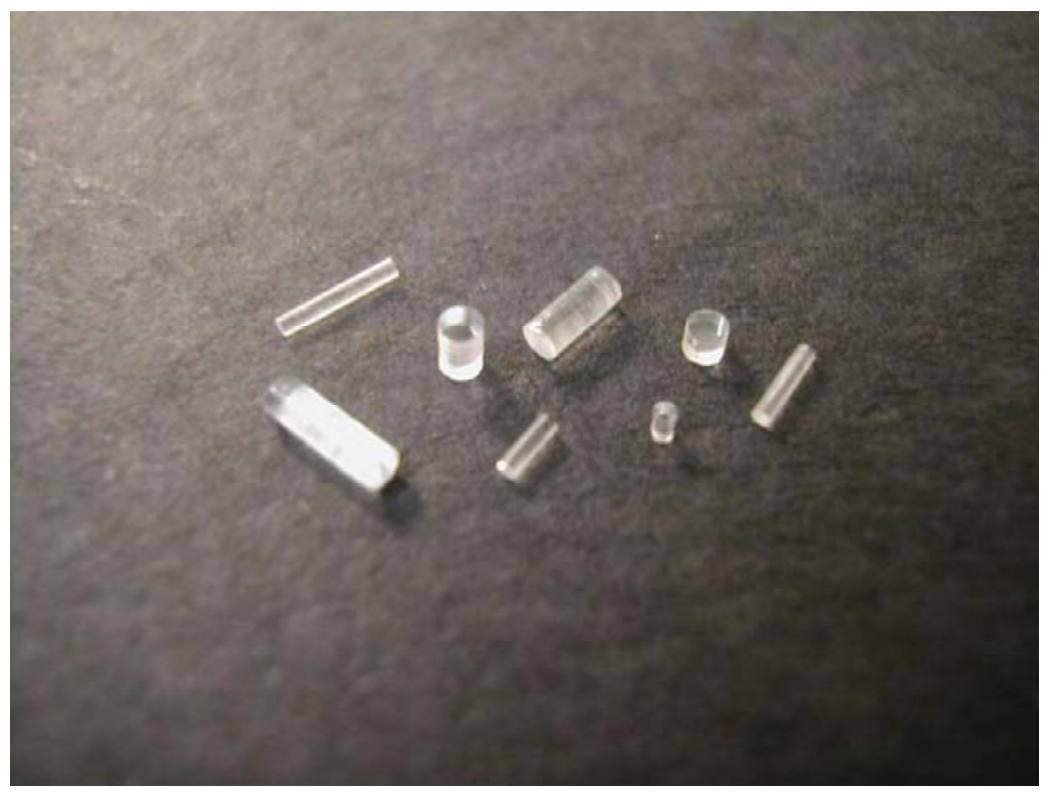

Figure 4. Cut and Polished Radiation Sensitive $\mathrm{Al}_{2} \mathrm{O}_{3}: \mathrm{C}$ Fibers 


\subsection{Sensor and Reader Construction and Testing}

The majority of the work during Phase I centered on construction and testing of the sensor and reader. First, a sensor was constructed and tested followed by construction and testing of a portable reader. Construction of the portable reader, which was originally scheduled for Phase II, became possible because of the success of initial efforts of construction of the sensor. Construction and testing of the sensor and portable reader will be discussed in this section.

\subsubsection{Sensor Construction and Testing}

The sensor consists of an $\mathrm{Al}_{2} \mathrm{O}_{3}$ fiber attached to a $\mathrm{SiO}_{2}$ fiber optic cable. The ends of the $\mathrm{Al}_{2} \mathrm{O}_{3}$ and $\mathrm{SiO}_{2}$ fibers were optically polished using diamond paste and a specially designed holder. Several construction techniques were tested and examined. The procedure that was eventually adopted ensures optimum optical alignment between the $\mathrm{Al}_{2} \mathrm{O}_{3}$ fiber and the $\mathrm{SiO}_{2}$ fiber. Optical alignment does not necessarily coincide with an alignment of the physical central axes of the fiber and detector. This consisted of using an $\mathrm{X}-\mathrm{Y}$ positioner and a micro-vise to hold the $\mathrm{Al}_{2} \mathrm{O}_{3}$ fiber and to guide laser light from a diode laser down the $\mathrm{Al}_{2} \mathrm{O}_{3}$ fiber. A similar $\mathrm{X}-\mathrm{Y}$ positioner and vise was used to hold the $\mathrm{SiO}_{2}$ fiber. The other end of the $\mathrm{SiO}_{2}$ fiber was connected to an Ocean Optics spectrometer and computer. The alignment equipment is shown in Figure 5. The X-Y positioners were adjusted to ensure optimum optical coupling between the two fibers by monitoring the output of the $\mathrm{SiO}_{2}$ fiber for maximum signal, as monitored by the computer. The $\mathrm{Al}_{2} \mathrm{O}_{3}$ fiber was then cemented to the $\mathrm{SiO}_{2}$ fiber using index-matching cement (resin). The resin was cured using UV irradiation emitted by the unfiltered light from a deuterium lamp. Separate tests of the effect of UV illumination on the dosimetry properties of the $\mathrm{Al}_{2} \mathrm{O}_{3}$ fibers indicated that the sensitivity of the fibers could be increased by pre-irradiation exposure to UV light. Thus, the UV curing process has an added benefit of increasing the sensitivity of the $\mathrm{Al}_{2} \mathrm{O}_{3}$ fiber to ionizing radiation. After curing, the result is a physically robust and optically optimized probe for use in dosimetry measurements.

Several fibers of different diameters were constructed using the described procedure. They were tested on the bench top by exposing them to beta or $\mathrm{X}$ radiation and monitoring both the radioluminescence and optically stimulated luminescence signals. Radioluminescence produced when large quantities of electrons and holes are created by incident radiation over a short period of time and they immediately recombine. The recombination results in the spontaneous emission of light that is also called prompt luminescence. Radioluminescence occurs at high dose rates. These measurements, which used doses that varied from 1 rad to several krad, showed that the OSL emission was proportional to the dose while the radioluminescence signal was proportional to dose rate. The implication of these results is that the OSL signal will provide an accurate measurement of the dose that is independent of the dose rate. 


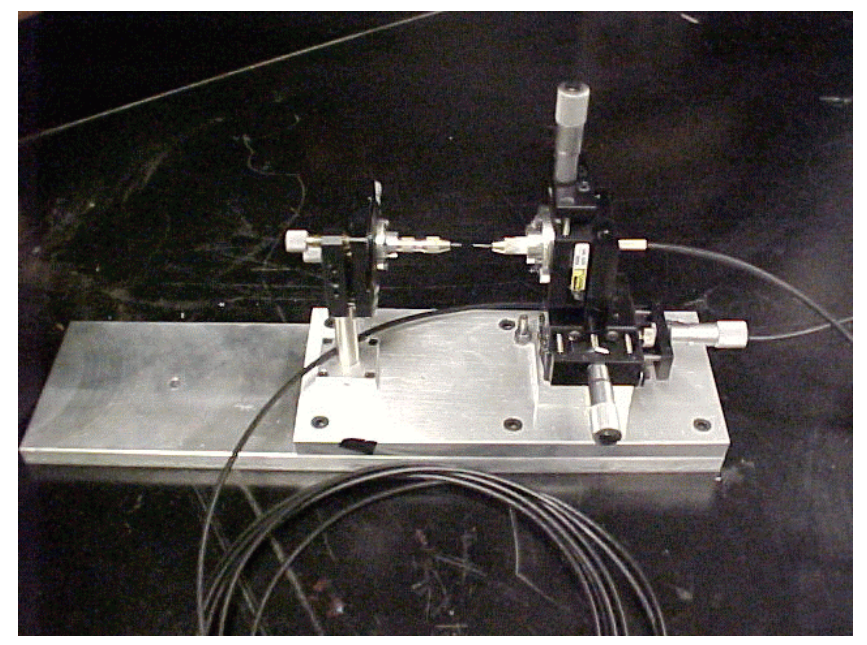

Figure 5. Dosimeter and Fiber Optic Alignment Equipment

Measurements of the sensitivity of the aluminum oxide fibers were completed. The minimum measurable dose (MMD) was defined as that dose which gives a thermoluminescent (TL) or optically stimulated luminescence (OSL) signal of 3 standard deviations $(\sigma)$ above the background signal. Dose response curves were obtained and extrapolation of the response to the background + $3 \sigma$ level yielded the MMD. Three types of fibers were tested: (1) $2 \mathrm{~mm}$ diameter, $9 \mathrm{~mm}$ long $\mathrm{Al}_{2} \mathrm{O}_{3}$ fiber; (2) $550 \mu \mathrm{m}$ diameter, $3 \mathrm{~mm}$ long $\mathrm{Al}_{2} \mathrm{O}_{3}$ fiber and; (3) $600 \mu \mathrm{m}$ diameter, $5 \mathrm{~mm}$ long fiber. The MMDs are provided in Table 1.

\begin{tabular}{|c|c|}
\hline Sample & MMD \\
\hline 2 mm diameter, $9 \mathrm{~mm}$ long & $0.08 \mathrm{mGy}(8 \mathrm{mrem})$ \\
\hline $550 \mu \mathrm{m}$ diameter, $3 \mathrm{~mm}$ long & $0.5 \mathrm{mGy}(50 \mathrm{mrem})$ \\
\hline $600 \mu \mathrm{m}$ diameter, $5 \mathrm{~mm}$ long fiber* & $2.5 \mathrm{mGy}(250 \mathrm{mrem})$ \\
\hline
\end{tabular}

Table 1. Minimum Detectable Dose for three different growths of Al2O3 fibers. *This material was grown using an old method and the fibers are not "dosimetry grade"

Based on the results in Table 1, it is concluded that recent fiber growth methods used by Landauer in the production of the $\mathrm{Al}_{2} \mathrm{O}_{3}$ fibers are able to achieve the required MMD of $1 \mathrm{mGy}$ or less. Thus the growth method exceeds the success criteria for the milestone.

After the development of a portable reader, the MMD for the sensor was determined by exposing the sensor to a ${ }^{60} \mathrm{Co}$ source to obtain the peak OSL count as a function of dose. The data were fit to a 
straight line using linear regression and the MMD was determined to be the value that is 3 standard deviations above the background signal. The data from these measurements is given in Figure 6. Based on the data in this figure, the MMD was determined to be $1.5 \mathrm{mrad}$.

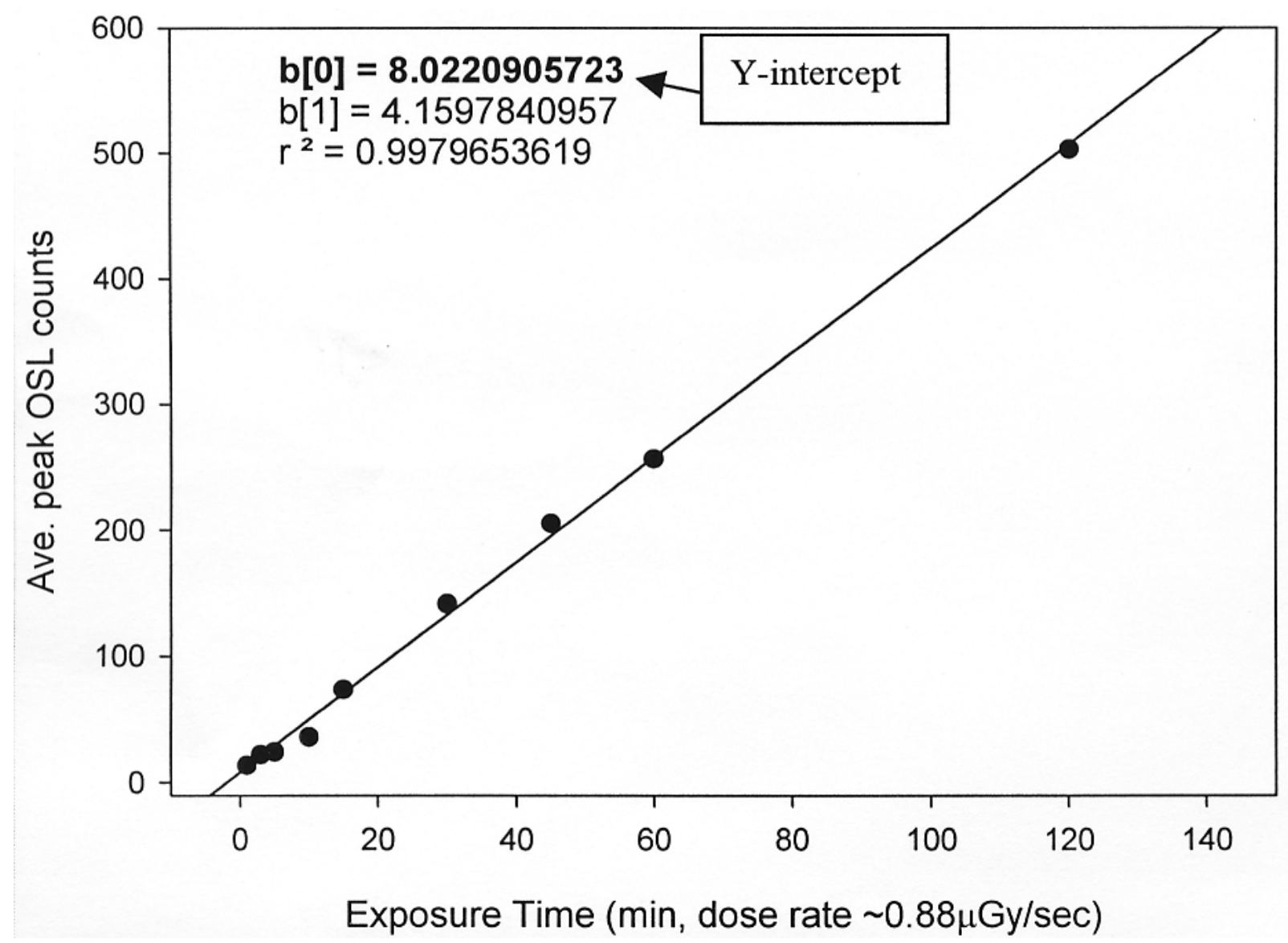

Figure 6. Data Used to Determine the Minimum Detectable Dose for the Sensor

The exposure time required to measure soil concentrations can be determined from the MMD. Calculations were performed using VARSKIN Mod $2^{7}$ that modeled the source as an "infinite" 3dimensional right cylinder and the sensor as a right cylinder with a diameter of $9 \mathrm{~mm}$ and a thickness of $2 \mathrm{~mm}$. Using the MMD from Figure 6 of $1.5 \mathrm{mrad}$, it has been determined that soil concentrations of $50 \mathrm{pCi} / \mathrm{cm}^{3}$ could be measured after an exposure time of 200 hours for ${ }^{90} \mathrm{Sr} /{ }^{90} \mathrm{Y}, 150$ hours $(6.25$ days) for ${ }^{137} \mathrm{Cs}$, and 54000 hours (6 years) for ${ }^{99} \mathrm{Tc}$. These values represent three standard deviations of the measure of uncertainty above natural background levels, which were assumed to be $50 \mu \mathrm{rad} / \mathrm{h}$. Clearly this monitor is not suitable for measuring ${ }^{99} \mathrm{Tc}$. In order to compare these numbers to a soil release level in $\mathrm{pCi} / \mathrm{g}$, it is necessary to multiply the release level by the soil density. Therefore, measuring a soil release level of $50 \mathrm{pCi} / \mathrm{g}$ in a solid with a density of $0.5 \mathrm{~g} / \mathrm{cm}^{3}$ requires an exposure time of 100 hours (4 days) for ${ }^{90} \mathrm{Sr} /{ }^{90} \mathrm{Y}$ and 75 hours (3 days) for ${ }^{137} \mathrm{Cs}$. These data show that the monitor is capable of providing long-term, in situ measurements of ${ }^{90} \mathrm{Sr} /{ }^{90} \mathrm{Y}$ and ${ }^{137} \mathrm{Cs}$ soil 
contamination levels at intervals shorter than the typical 90-day cycle used for soil sampling using current techniques.

Typically, contamination levels in soil that is undergoing remediation are 10 to 100 times higher than the soil release level. For example, to measure a contamination level of $5 \mathrm{nCi} / \mathrm{g}$ in a solid with a density of $0.5 \mathrm{~g} / \mathrm{cm}^{3}$ would require an exposure time of 1 hour for ${ }^{90} \mathrm{Sr} /{ }^{90} \mathrm{Y}$ and 45 minutes for ${ }^{137} \mathrm{Cs}$. Thus it appears that the subsurface monitor is extremely useful for "realtime" monitoring of ${ }^{90} \mathrm{Sr} /{ }^{90} \mathrm{Y}$ and ${ }^{137} \mathrm{Cs}$.

Results of the minimum measurable soil contamination levels for the two different contaminants are presented in Figures 7 and 8. Note that the soil contamination level in these figures is in units of $\mathrm{nCi} / \mathrm{cm}^{3}$. Measurable contamination levels in units of $\mathrm{nCi} / \mathrm{g}$ for the same exposure time can be obtained by multiplying the soil concentration by the density of the soil.

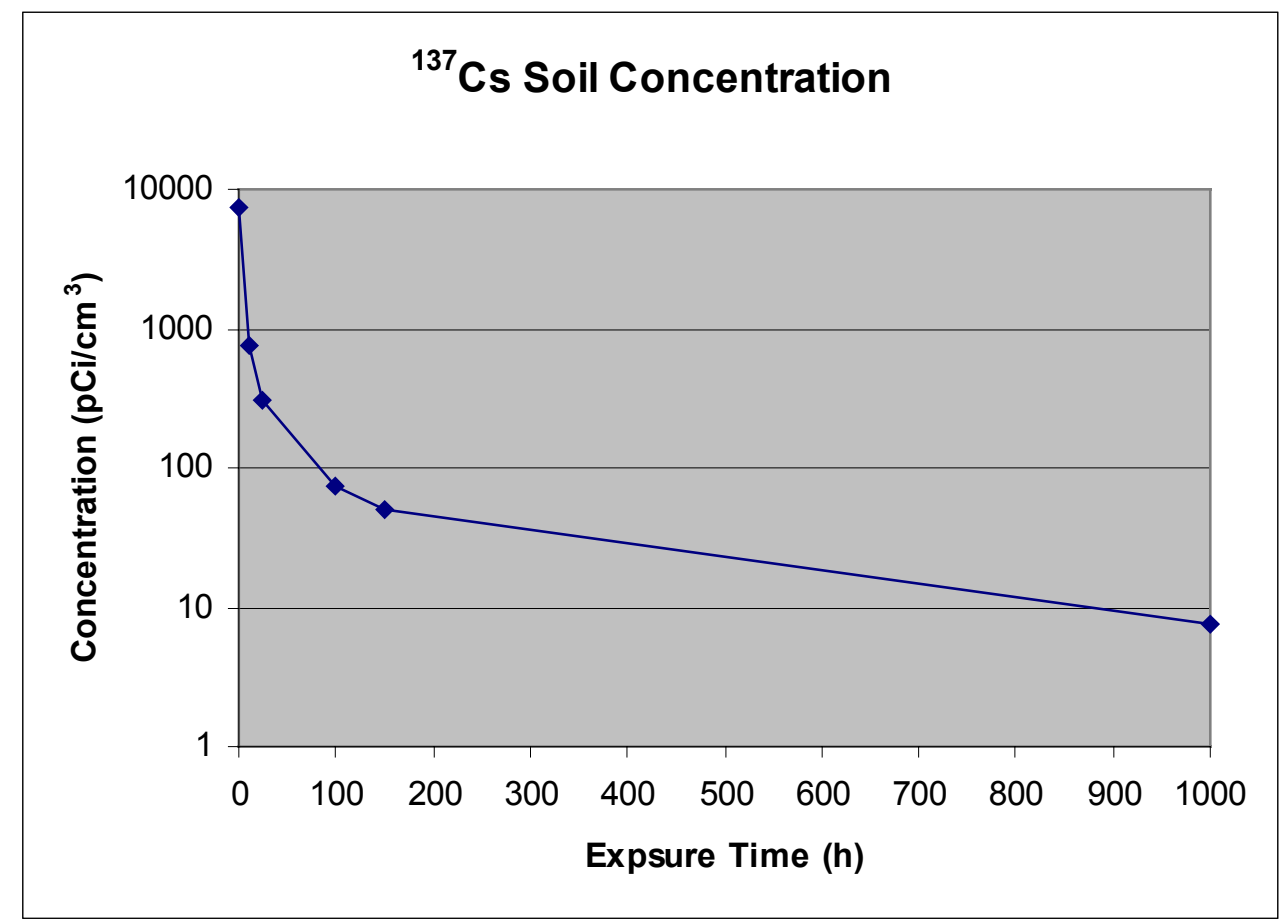

Figure 7. ${ }^{137}$ Cs Concentration as a Function of Exposure Time 


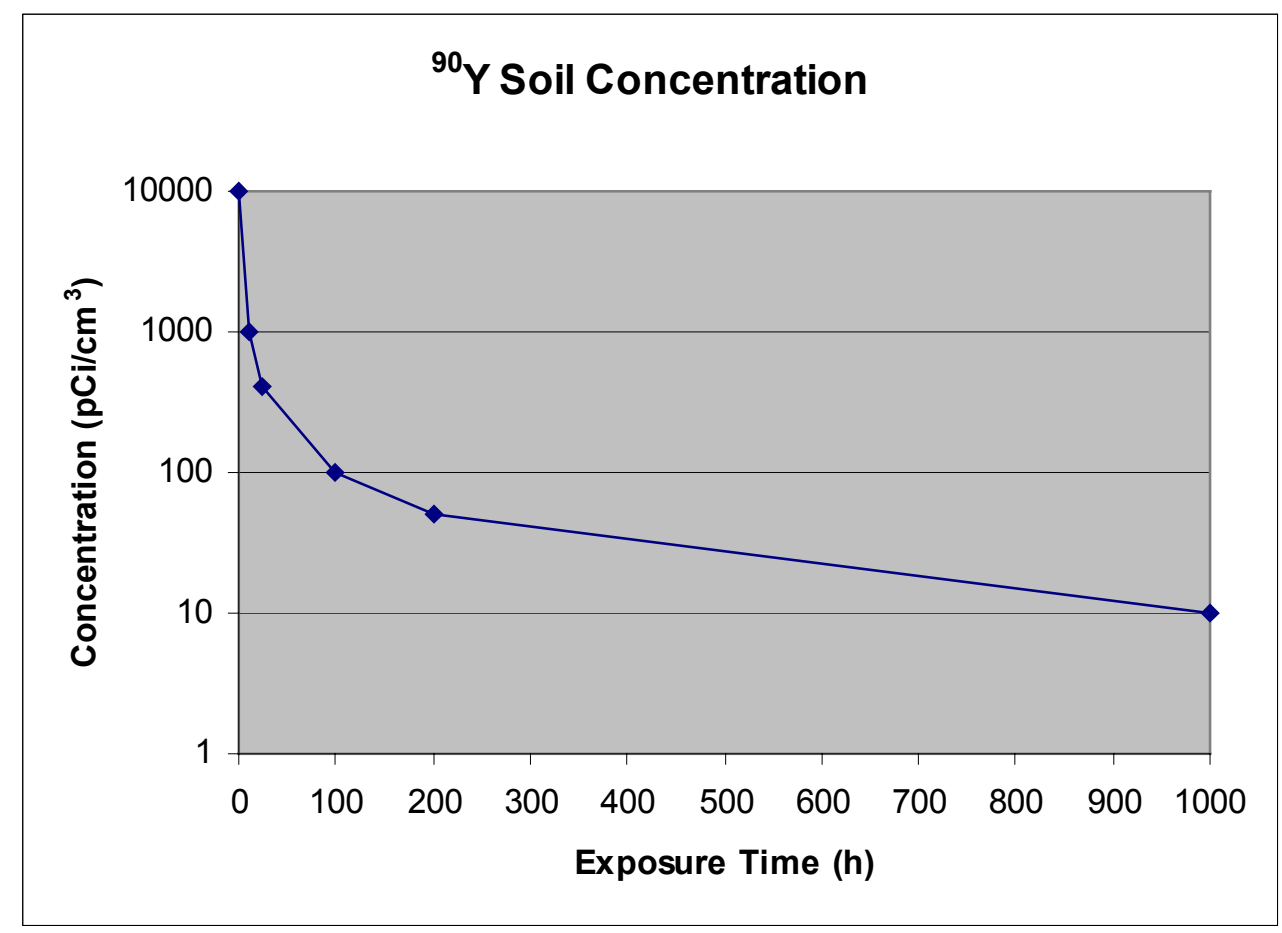

Figure 8. ${ }^{90}$ Y Concentration as a Function of Exposure Time

It is also useful to consider the minimum soil concentration that can be measured in a 24 hour period. Table 2 contains these data in units of $\mathrm{nCi} / \mathrm{cm}^{3}$. Minimum contamination levels in units of $\mathrm{nCi} / \mathrm{g}$ for the same exposure time can be obtained by multiplying the soil concentration by the density of the soil.

\begin{tabular}{|c|c|}
\hline Contaminant & Soil Concentration Level (pCi/cm $\mathbf{3})$ \\
\hline${ }^{137} \mathrm{Cs}$ & 313 \\
\hline${ }^{90} \mathrm{Y}$ & 417 \\
\hline
\end{tabular}

Table 2. Detectable Level of Contamination after a 24 hour Exposure

\subsubsection{Reader Construction and Testing}

The OSL reader for the project was constructed to work with a single fiber probe. Light from a continuous wave $(\mathrm{CW}) \mathrm{Nd}: \mathrm{YAG}$ laser is focused onto the fiber and is transmitted down the fiber to the $\mathrm{Al}_{2} \mathrm{O}_{3}$ detector. Luminescence form the detector is transmitted back through the fiber to a dichroic mirror (beamsplitter), where it if reflected into a photomultiplier tube as shown in Figure 9. The dimensions of the reader are 9 inches by 7 inches. Therefore, this reader is a portable prototype. Construction of a portable reader was not initially anticipated until Phase II of this effort. 


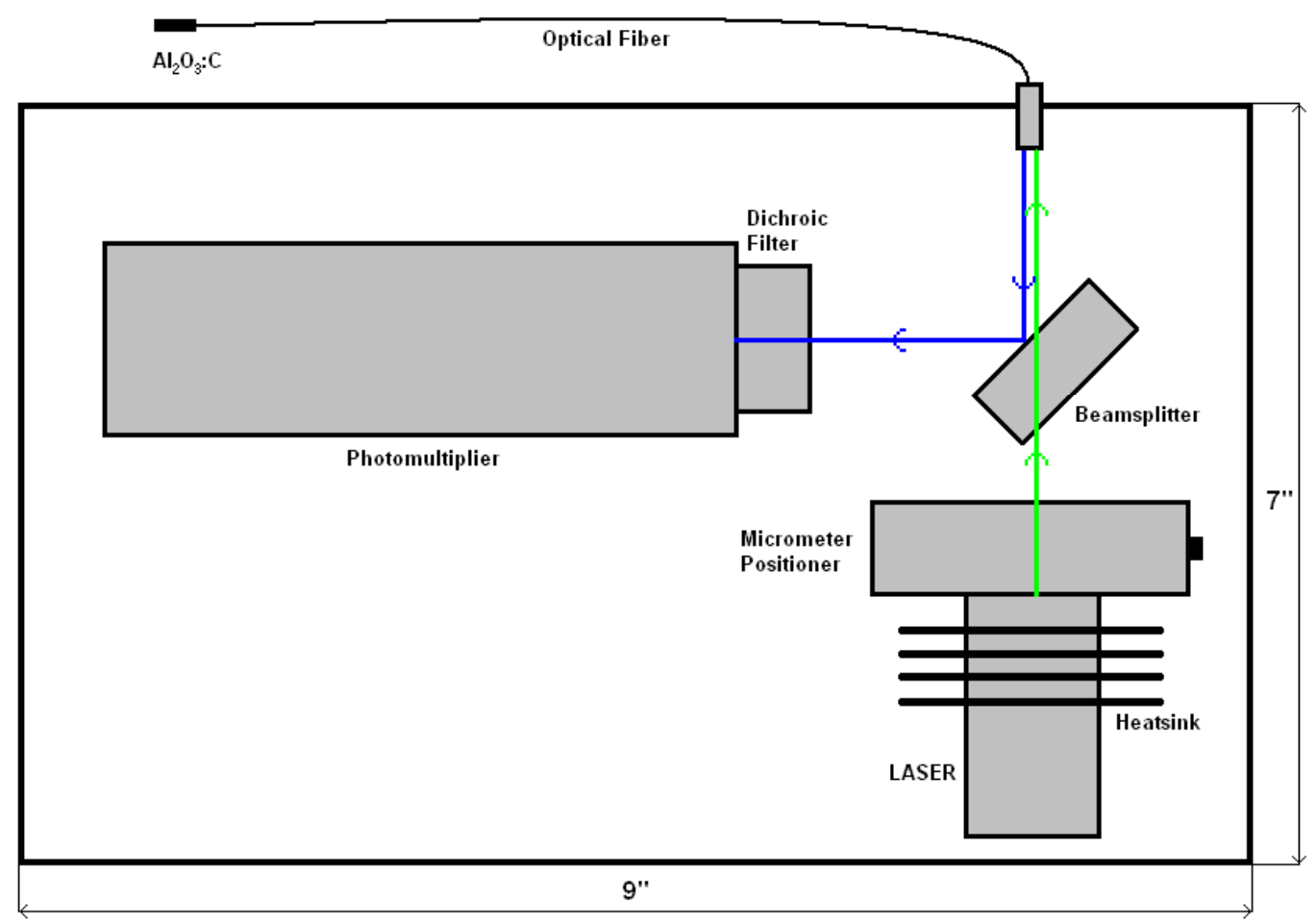

Figure 9. Schematic Diagram of the Portable Reader

Figures 10 and 11 show details of the portable reader, including a view of the internal components of the reader. Figure 10 shows the reader (background), the red optic channel that houses the fiber, and the laptop computer used to record the data and control the instrument. Figure 11 shows the internal components of the reader, including the silver laser, the black photomultiplier tube (PMT) and the half-silvered mirror between the laser and PMT. The sensor is attached to the alignment fixture at the bottom of the image directly in line with the laser. The wiring in Figure 11 is the power supply for the laser.

Most of the bench tests of the probe used a $0.5 \mu \mathrm{m}{ }^{137} \mathrm{Cs}$ gamma source and $10 \mathrm{mCi} 90 \mathrm{Y} / 90 \mathrm{Sr}$ beta source and sensor consisting of a $9 \mathrm{~mm}$ long, $2 \mathrm{~mm}$ diameter $\mathrm{Al}_{2} \mathrm{O}_{3}$ fiber connected to a $30 \mathrm{~cm}$ long, $2 \mathrm{~mm}$ diameter silica fiber optic channel. Figures 12 and 13 show the sensor with and without stimulation, respectively. The bright line of light in Figure 13 indicates the interface between the $\mathrm{Al}_{2} \mathrm{O}_{3}$ fiber and the silica fiber optic channel. 


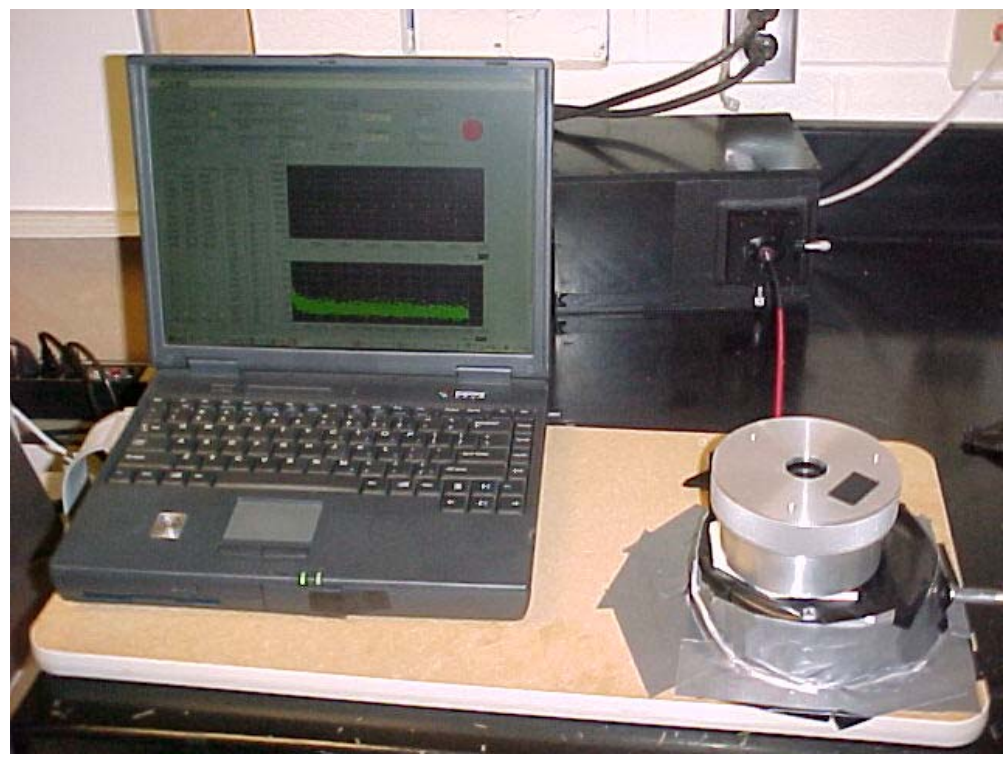

Figure 10. The OSL Reader System, Including the Reader (Background), the Red Fiber Optic Channel, the Irradiation/Readout Chamber, and a Laptop Computer for Data Acquisition

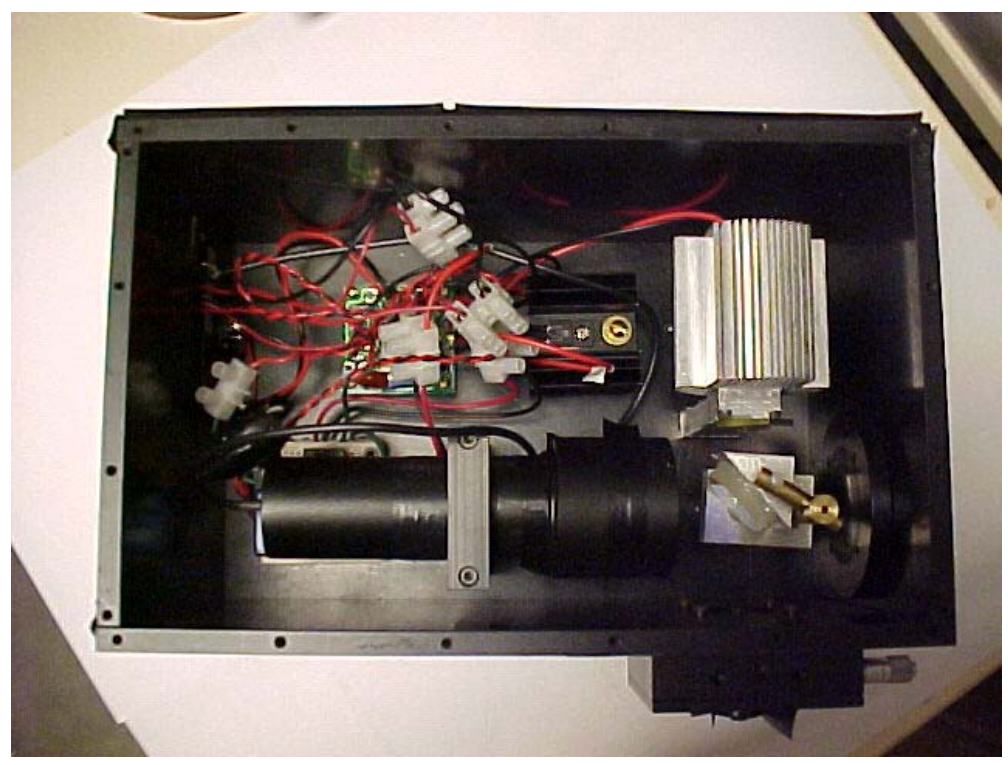

Figure 11. Interior of OSL Reader Showing the Silver Laser, the Black PMT, the Half-Silvered Mirror (between Laser and PMT), and the Laser Power Supply 


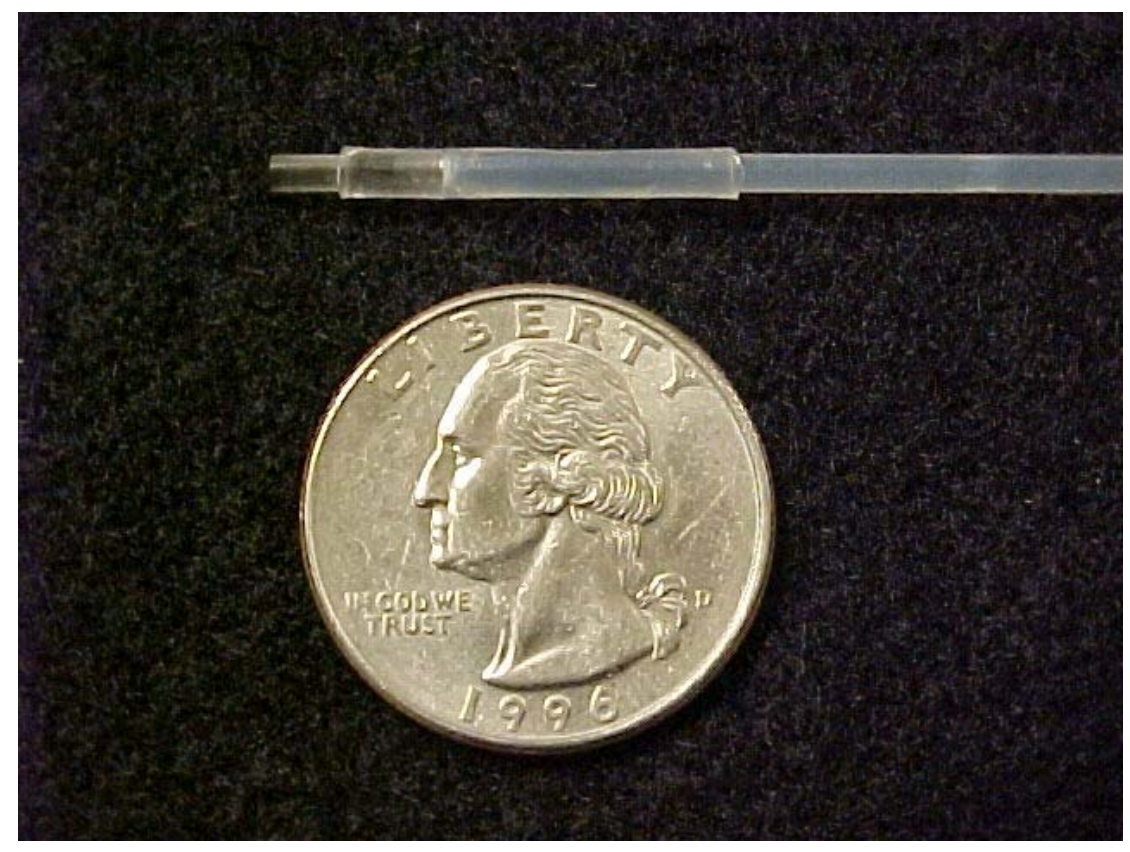

Figure 12. Unlighted Sensor Showing Interface between the $\mathrm{Al}_{2} \mathrm{O}_{3}$ Fiber and the Silica Fiber Optic Channel

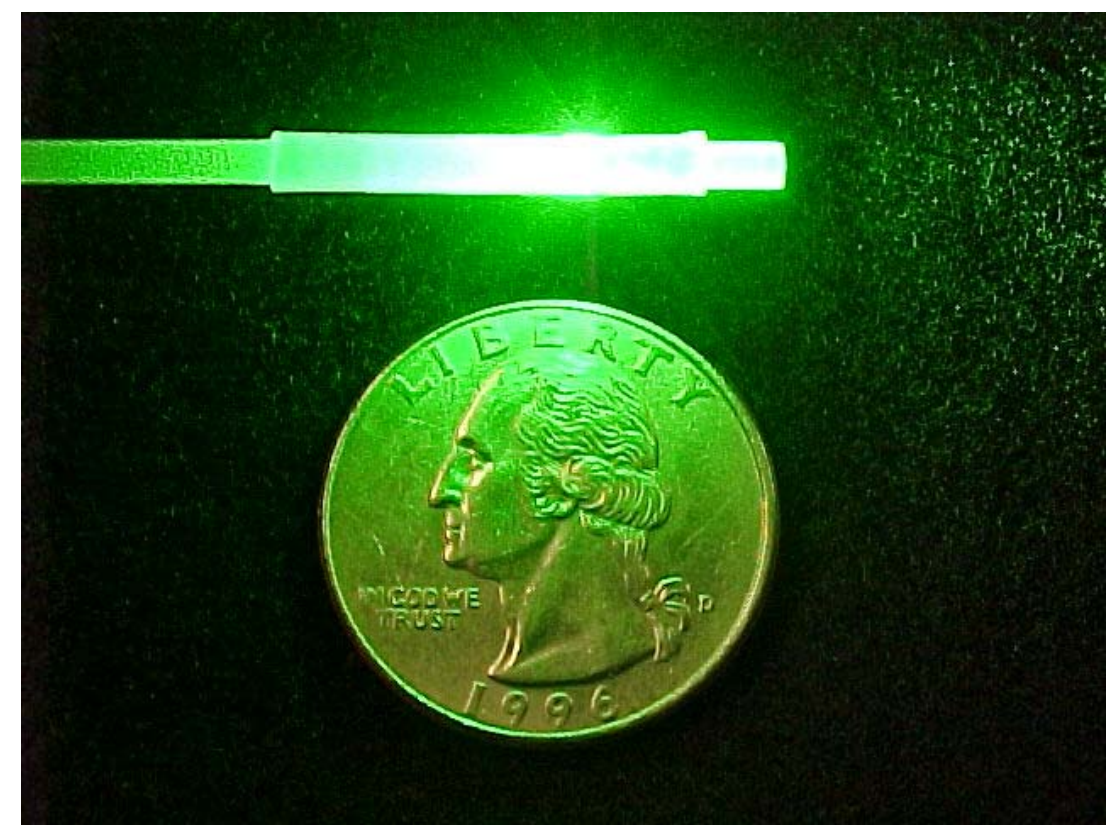

Figure 13. Stimulated Sensor Showing Light Scatter at the Fiber/Fiber Optic Interface

Success criteria were developed to demonstrate that the sensor could meet the objectives of this effort. The three success criteria included: 1) Perform measurements with the sensor for both 
gamma and beta radiation with a standard deviation of $10 \%$ or less; 2) Demonstrate the ability of the sensor to discriminate between gamma and beta radiation; and 3) Obtain similar or relatable results for differing lengths of fiber optic cable. The results of these measurements are presented in the following subsection.

\subsubsection{Measurement Repeatability}

To measure the repeatability of the sensor for gamma dose measurements, a measurement sequence was followed. The measurement sequence was to initially read a dark count, for ten minutes, during which period the laser is turned off. This was followed by a period of half an hour during which the laser remained off (along with the PMT), but during which the gamma source irradiated the sample. This period is considered the "dose period." After the half-hour gamma dose period, the laser and PMT were activated and the optically stimulated luminescence (OSL) signal was read for ten minutes. This ten-minute read was then followed by another 30-minute dose period. This pattern of half hour dose and ten minute read was repeated a total of twenty times, and is summarized below:

1. 10 minute dark count period (laser off, PMT on, gamma source closed)

2. 30 minute dose period (gamma source open, laser off, PMT off)

3. 10 minute read period (gamma source open, laser on, PMT on)

4. Repeat steps 2 and 3 for the duration of the experiment

Note that the read period (step 3) measures both the RL signal and the OSL signal together. Separate measurements of the RL signal indicate that the intensity of the RL is over an order of magnitude smaller than the OSL signal.

The results indicated a large signal during the first two or three read periods. The cause of this is not identified, but may be associated with radiation leakage around the closed source, or incomplete zeroing from previous measurements. However, this "over-response" decreases steadily and stabilizes after several initial runs - which is to be expected with either of these causes since once the large signal has been fully depleted, one only measures the signal due to the 30 minute dose periods. Representative results taken after stabilization can be seen in Figure 14. We obtain a standard deviation of approximately $1.59 \%$ during this stable period. This standard deviation clearly exceeds the success criterion for gamma dose repeatability. 


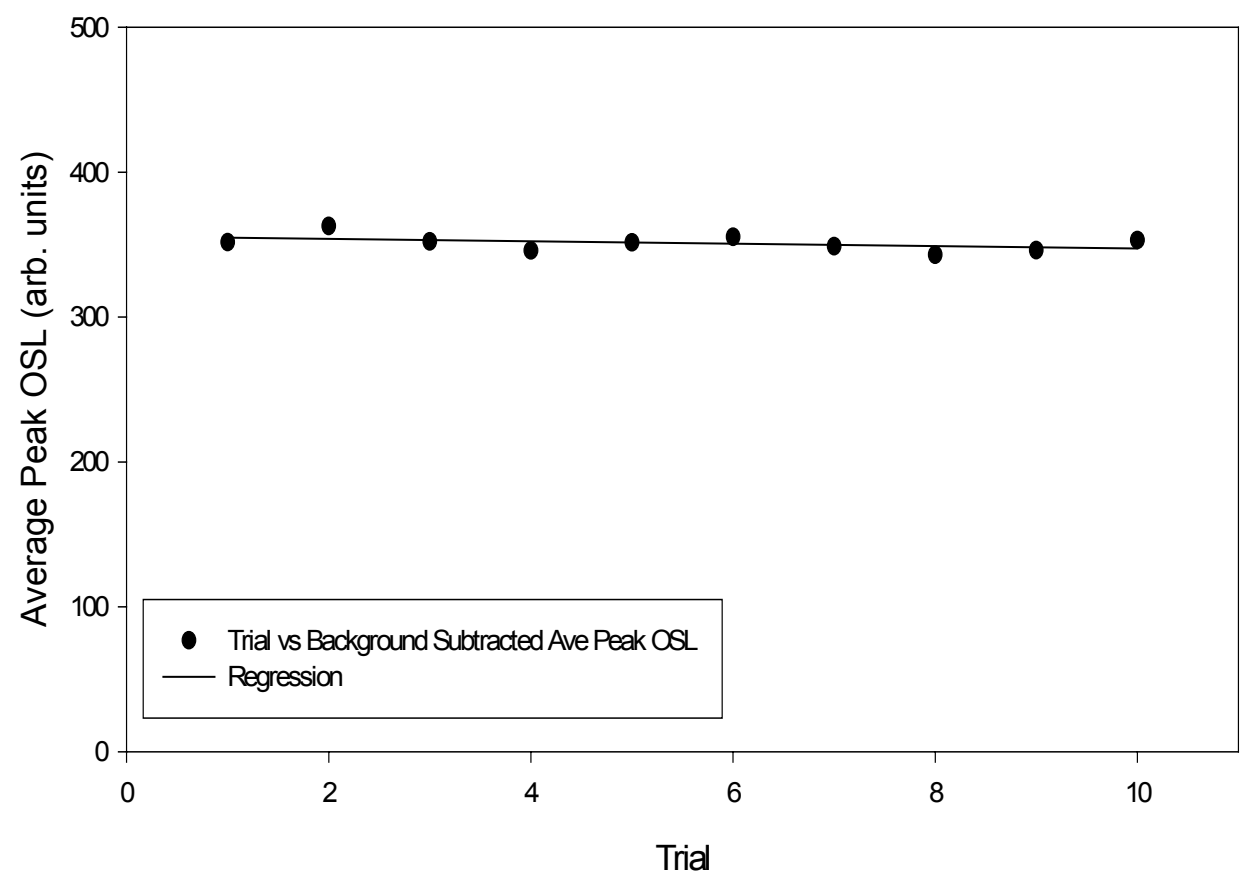

Figure 14. Results of the Gamma Dose Repeatability Measurements

The same sequence as above could not be used for ${ }^{90} \mathrm{Sr}$ beta dose repeatability measurements since the beta source is orders of magnitude more active than the ${ }^{137} \mathrm{Cs}$ gamma source. The estimated dose rate for the beta source is $1.8 \mathrm{mGy} / \mathrm{s}$ compared to $0.3 \mu \mathrm{Gy} / \mathrm{s}$, which is the estimated dose rate for the ${ }^{137} \mathrm{Cs}$ source. At these high dose rates, a large radioluminescence signal would be observed during the OSL read period. The irradiation and readout sequence was therefore modified in the following manner:

1. $10 \mathrm{~s}$ dark count period (beta source closed; laser off, PMT on)

2. $4 \mathrm{~s}$ dose period (beta source open, laser off, PMT on)

3. $10 \mathrm{~s}$ dark count period (beta source closed, laser off, PMT on)

4. 10 minutes read period (beta source closed, laser on, PMT on)

The addition of step 3 allows for the emission of the RL signal before measuring the OSL signal. Figure 15 shows the results of the beta dose repeatability experiment. The points in this case represent the background-subtracted integrated area under the OSL curve counted over the first three minutes of laser exposure. The background was taken as the average of the last few readings. One standard deviation was determined to be $2.85 \%$. Again, this standard deviation clearly exceeds the success criterion for beta measurement repeatability. 


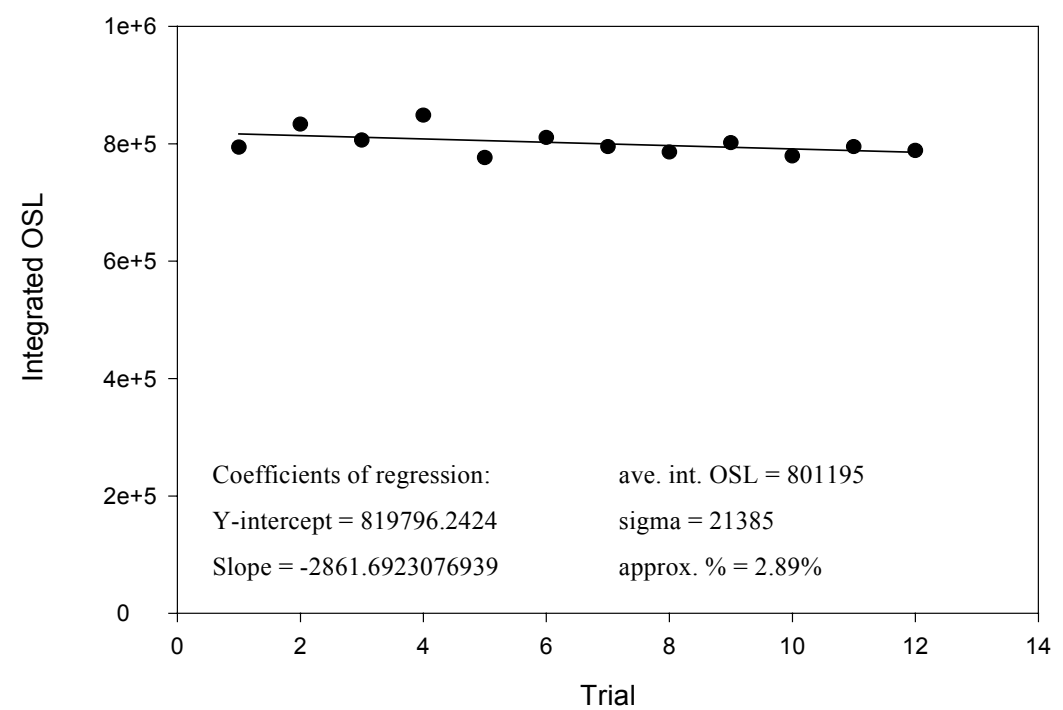

Figure 15. Results of the Beta Dose Repeatability Measurements. The OSL Signal Has Been Corrected for Background

\subsubsection{Discrimination between Beta and Gamma Radiation}

The same fiber was used for the beta-gamma discrimination measurements. The fiber was fitted with an end cap, made from an Al cylinder with $5 \mathrm{~mm}$ thick walls (Figures 16 and 17). This thickness was judged to provide sufficient attenuation of the ${ }^{90} \mathrm{Sr} /{ }^{90} \mathrm{Y}$ beta particles with only a minimum attenuation of the gamma radiation. As an indication of the extent of attenuation of the beta signal the radioluminescence (RL) from the irradiation fiber in the beta source was monitored both with and without the end cap. The results are shown in Figures 18 and 19.

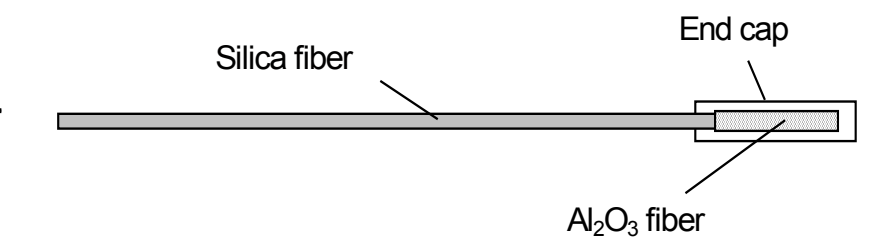

Figure 16. Schematic Diagram of the Fiber Probe with End Cap 

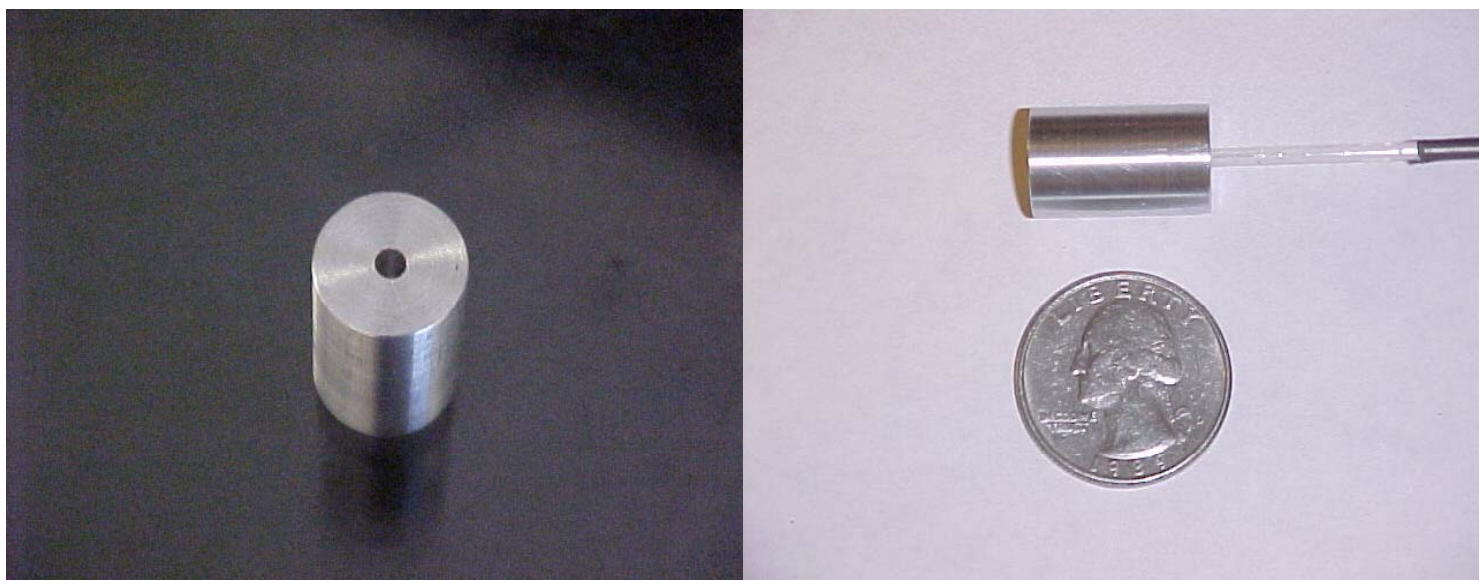

Figure 17. Beta Shield End Cap Alone and in Place

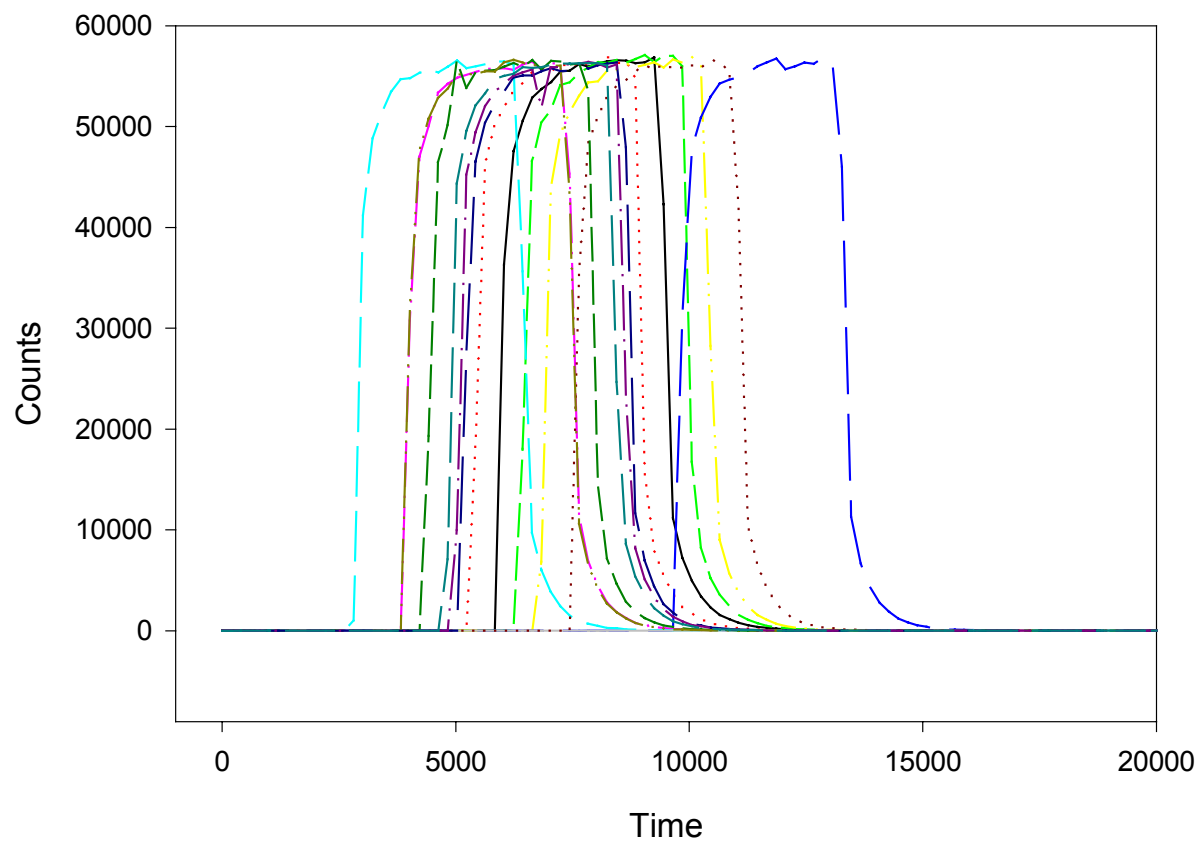

Figure 18. Multiple Radioluminescence Readings for a Four-Second Beta Irradiation without the End Cap 


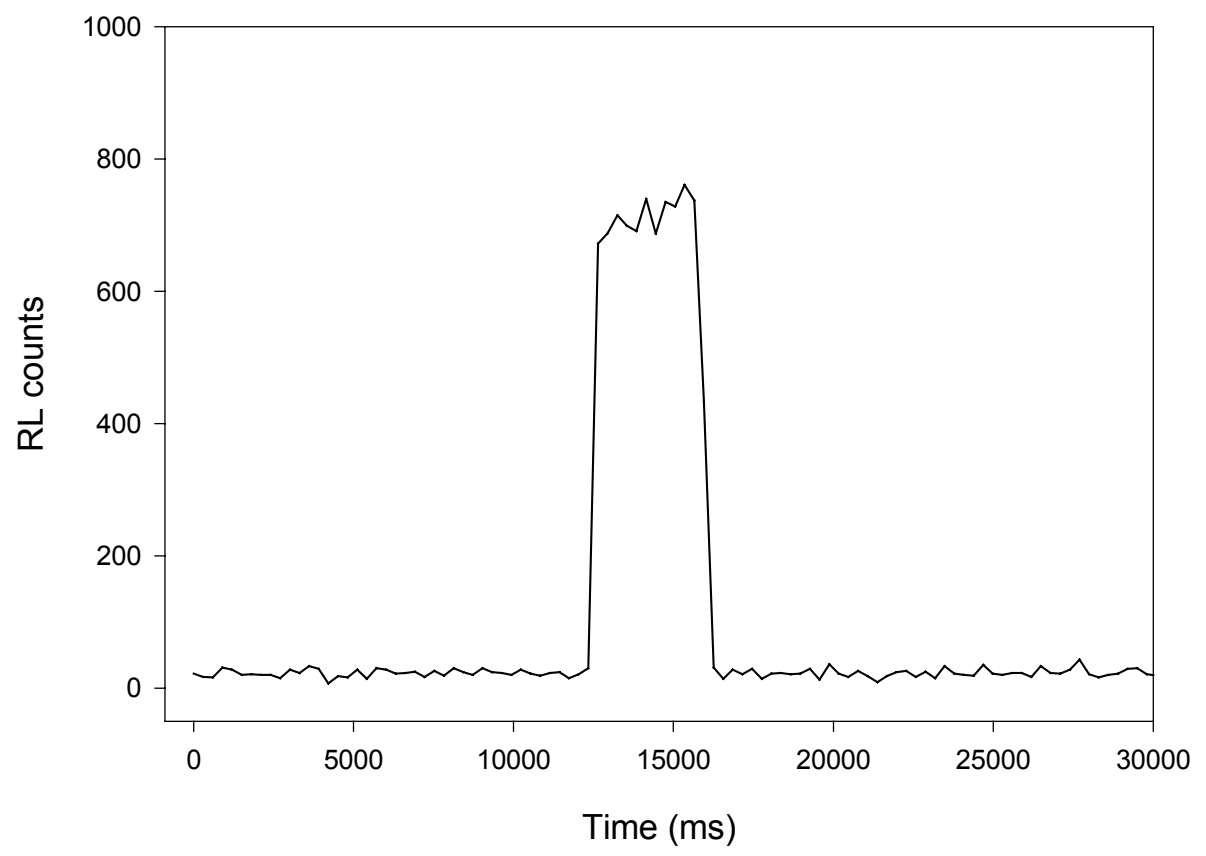

Figure 19. Single Radioluminescence Reading for a Four-Second Beta Irradiation the End Cap in Place

The difference in the intensity of the RL in these figures is approximately a factor of 80 , and indeed the signal observed in Figure 19 is probably primarily due to bremsstrahlung radiation. Since the unshielded dose rate from the beta source is $1.8 \mathrm{mGy} / \mathrm{s}$, the effective dose rate with the end cap in place is $2.2 \mu \mathrm{Gy} / \mathrm{s}$. This is the dose rate from the ${ }^{137} \mathrm{Cs}$ gamma source, and thus a test of beta-gamma discrimination using this weak gamma source was not feasible. Instead, we used a ${ }^{60} \mathrm{Co}$ source that delivers a dose rate of approximately $7 \mathrm{mGy} / \mathrm{s}$. Since it is not possible to insert the fiber probe into the latter source, the $\mathrm{Al}_{2} \mathrm{O}_{3}$ dosimeter was removed from the end of the silica fiber and irradiated. First, the dosimeter and end cap were placed in the ${ }^{60} \mathrm{Co}$ gamma source. Second, the dosimeter and end cap was placed in the ${ }^{90} \mathrm{Sr} r{ }^{90} \mathrm{Y}$ source. Finally, the dosimeter was placed in the gamma source without the end cap. After each irradiation there followed a 10-minute OSL readout. The experimental sequence was:

1. ${ }^{60}$ Co source, with end cap

2. OSL read for 10 minutes

3. ${ }^{90} \mathrm{Sr} /{ }^{90} \mathrm{Y}$ source, with end cap

4. OSL read for 10 minutes

5. ${ }^{60}$ Co source, without end cap

6. OSL read for 10 minutes.

The dose delivered during each irradiation was $7.1 \mathrm{mGy}$.

The results of this test are illustrated in Figure 20, where it can be seen that the two gamma 
irradiations gave the same result, whereas the beta-induced OSL signal was several orders of magnitude smaller. These data indicate that the 5-mm end cap provides sufficient attenuation of the beta signal without significantly affecting the gamma signal. Thus the end cap can be used to discriminate between beta and gamma radiation, meeting the success criteria for this objective.

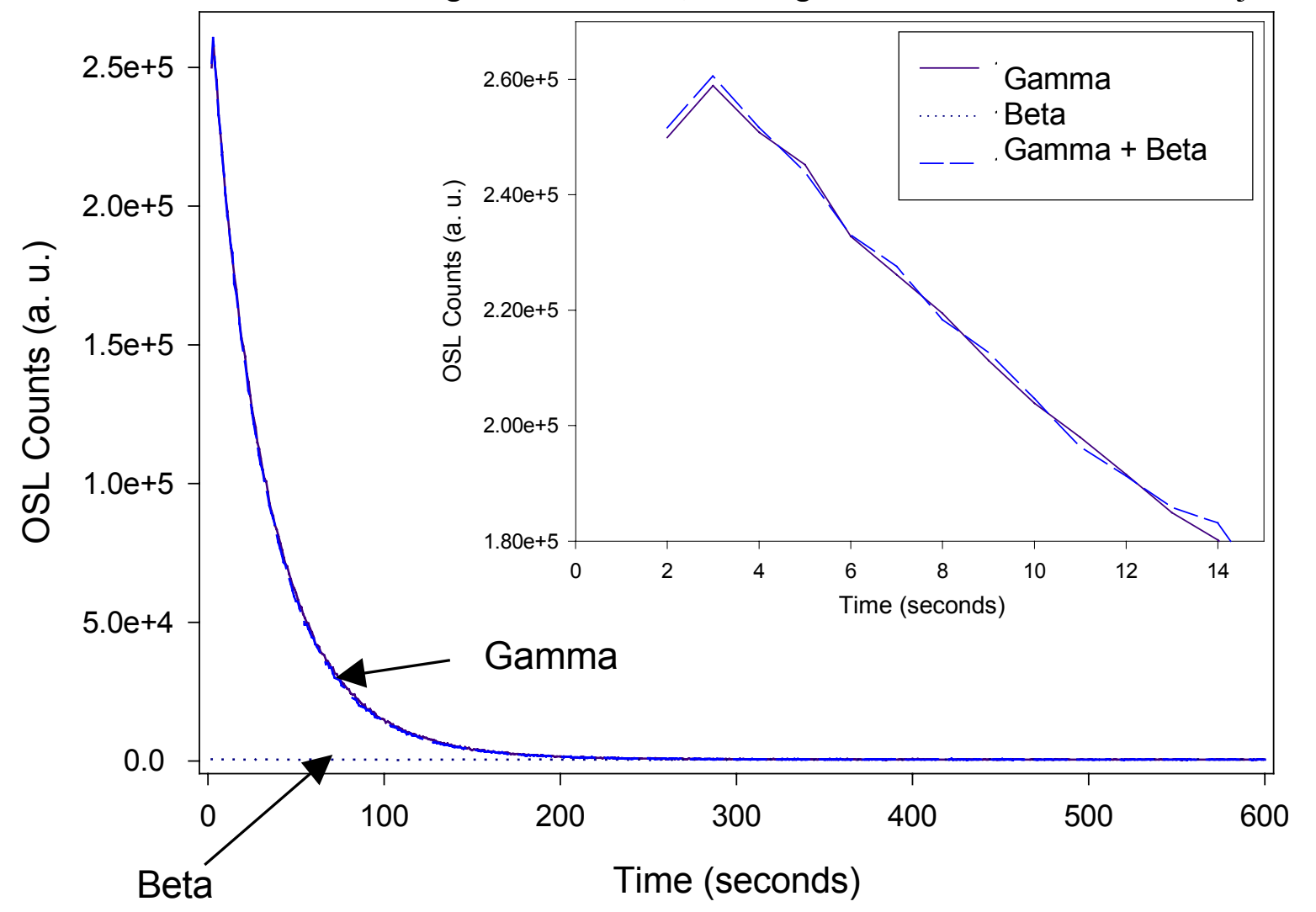

Figure 20. Results of Irradiation of Fiber with End cap by Gamma and Beta Radiation. The End Cap Effectively Shields the Beta Radiation. Inset: Results of Irradiation by Gamma Radiation with and without End Cap in Place. There Is No Significant Difference Between Responses to Gamma Radiation

\subsubsection{Tests on Different Lengths of Fiber Optic Cable}

The signal measured at the end of $1 \mathrm{~m}, 3 \mathrm{~m}$, and $10 \mathrm{~m}$ fiber optic cables was measured to determine if there was a relation between the signal transmitted and the length of the cable. The cable material is ESKA acrylic fiber optic cable developed and manufactured by Mitsubishi with a 1.47-mm core diameter. The $\mathrm{Al}_{2} \mathrm{O}_{3}$ fiber dosimeter used was $9 \mathrm{~mm}$ in length with a diameter of $2 \mathrm{~mm}$. The $\mathrm{Al}_{2} \mathrm{O}_{3}$ dosimeter was not attached to the fiber optic cable with epoxy so that the same dosimeter could be used for each length of fiber optic cable.

The dosimeter was attached to one end of each length of optical cable using heat-shrink tubing, while the other end of the cable terminated with an FC type optical fiber connector. The dosimeter 
was then exposed to $\mathrm{a} 0.5 \mu \mathrm{Ci}{ }^{137} \mathrm{Cs}$ gamma source for one half hour, after which the OSL of the dosimeter was read with a green $\mathrm{CW}$ laser for 5 minutes. This sequence of dose and OSL reading was performed 5 times with each cable-dosimeter probe. The integrated, background subtracted OSL signal of each measurement for each fiber are presented in Table 3. The ratios of the OSL signal from the longer cables to that of the 1-m cable are also given.

\begin{tabular}{|c|c|c|c|c|c|}
\hline & \multicolumn{3}{|c|}{ OSL through fiber optic cables: } & & \\
\cline { 2 - 4 } & & & & & \\
Trial: & $\mathbf{1}$ meter & $\mathbf{3}$ meters & $\mathbf{1 0}$ meters & OSL $_{\mathbf{3 m}} / \mathbf{O S L}_{\mathbf{1 m}}$ & OSL $_{\mathbf{1 0 m}} \mathbf{~} \mathbf{O S L}_{\mathbf{1 m}}$ \\
\hline 1 & 1659571 & 1251603 & 1302025 & 0.754 & 0.785 \\
\hline 2 & 1532371 & 1351436 & 1210806 & 0.882 & 0.790 \\
\hline 3 & 1633798 & 1513278 & 1210807 & 0.926 & 0.741 \\
\hline 4 & 1546904 & 1453252 & 1314430 & 0.939 & 0.850 \\
\hline Average: & 1590000 & 1390000 & 1260000 & 0.874 & 0.792 \\
\hline \% St Dev & 4.0 & 8.3 & 4.5 & & \\
\hline
\end{tabular}

Table 3. 3. OSL Signal as a Function of Fiber Optic Cable Length

The data in Table 3 indicate that there may be some attenuation of the OSL signal in the fiber optic cable. However, the attenuation is not severe and it may be an artifact of the use of heat shrink tubing to attach the dosimeter fiber to the cable. Heat shrink tubing does not ensure that the alignment is optically optimized. In future phases of this effort, these measurements will be repeated using permanently attached fibers. It is anticipated that the attenuation in the cable will be significantly diminished.

\subsection{Monitor Demonstration Siting}

Two sites have expressed interest in hosting a demonstration site for the monitor. Personnel at the Hanford Site have identified numerous sites in the 200 Area that would be suitable for demonstration of the contaminant monitor. In addition, personnel at the Nevada Test Site have identified locations near the waste disposal area that would provide a suitable demonstration site.

Because of uncertainties associated with funding for Phase II of this project, written agreements with these two entities were not pursued. Therefore, the success criterion for this objective, which was to obtain a written agreement to perform the demonstration, was not met. However, if funding for Phases II and III is obtained, a written agreement can be quickly reached. Therefore, the intent of the milestone has been achieved. 


\section{CONCLUSIONS}

This report has presented the results of the first phase of the project entitled "In-situ, Long-term Monitoring System for Radioactive Contaminants." Phase I of this effort included four objectives, each with specific success criteria.

The first objective was to produce dosimetry grade fibers and rods of aluminum oxide. The success criterion for this milestone was the production of aluminum oxide rods and fibers that have a minimum detectable activity (MDA) of 100 mrem or less. This milestone was completed, and the MDA for the rods was determined to be $1.53 \mathrm{mrem}$. Based on the MMD, the ability of the sensor to measure ${ }^{137} \mathrm{Cs},{ }^{90} \mathrm{Sr} r{ }^{90} \mathrm{Y}$, and ${ }^{99} \mathrm{Tc}$ was evaluated. It was determined that the sensor can measure the release limit of these radionuclides $\left(50 \mathrm{pCi} / \mathrm{cm}^{3}\right)$ in $150 \mathrm{~h}, 200 \mathrm{~h}$, and $54,000 \mathrm{~h}$, respectively. The monitor is adequate for measuring ${ }^{137} \mathrm{Cs}$ and ${ }^{90} \mathrm{Sr} /{ }^{90} \mathrm{Y}$ but is unsuitable for measuring ${ }^{99} \mathrm{Tc}$ in soil.

The second objective was to construct a prototype sensor (dosimeter and fiber optic channel). There were three success criteria for this milestone: 1) Perform measurements with the sensor for both gamma and beta radiation with a standard deviation of $10 \%$ or less; 2) Demonstrate the ability of the sensor to discriminate between gamma and beta radiation; and 3) Obtain similar or relatable results for differing lengths of fiber optic cable. These milestones were met. The sensor was able to measure gamma radiation repeatedly with a standard deviation of $3.15 \%$ and beta radiation with a standard deviation of $2.85 \%$. Data has been presented that demonstrates that an end cap can be used to discriminate between beta plus gamma and gamma radiation. It has been shown that some amount of attenuation occurs in longer fiber optic cables, but it is unclear if the attenuation is due to poor alignment of the dosimeter and the cable. This issue will be investigated further when more dosimeters are available so that the dosimeters can be permanently attached to the longer cables.

The third objective was to identify a demonstration site. The success criterion for this milestone was to obtain a written agreement from a DOE site to host the demonstration of the monitor during the third phase. Because of uncertainties in funding of the second and third phases of this effort, a written agreement was not obtained. Instead, verbal agreements were reached with both Hanford and the Nevada Test Site. It is believed that the verbal agreements meet the intent of the objective.

The final objective was to prepare the Draft Phase I Topical Report. The success criterion for this milestone was to have the report accepted by NETL. It is anticipated that this objective will be met.

\section{FUTURE WORK}

Future work for this project includes Phases II and III, each anticipated to last one year. Phase II will focus on development of a portable reader with a pulsed laser, which was purchased during Phase I of this effort. The pulsed laser is pictured in Figure 21. The pulsed laser should significantly increase the stability of the signal and increase the sensitivity of the monitor. The 
second phase will also include growing more aluminum oxide fibers with improved dosimetry properties, demonstration of proof-of-principle of a multiplexing reader, laboratory scale measurements with the reader, and identifying any technical or economic issues with the reader and fibers. The second phase will also include measurements of the calibration factors for the sensor for both beta and gamma radiation. Finally, a commitment from personnel at the demonstration site will be obtained, Environmental, Safety and Health (ES\&H) risks and regulatory issues associated with the demonstration will be identified, and a plan to address the identified risks or issues will be initiated.

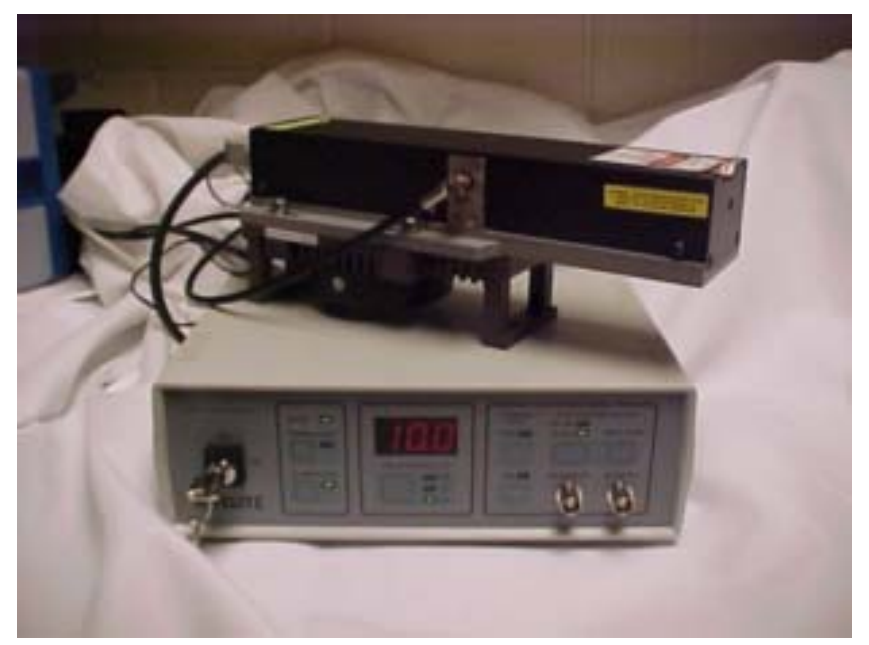

Figure 21. Pulsed Laser and Power Supply to be Incorporated into a Portable Reader

The third and final phase will focus on finalizing the reader so that any technical issues identified during the second phase are addressed. The primary activity of the third phase will be demonstrating the subsurface monitor during a pilot test at a DOE site, including implementation of the ES\&H plan, and identifying and addressing any technical difficulties encountered during the demonstration. 


\section{REFERENCES}

1. S. Soumana, J. Fain, D. Miallier, M. Montret, T. Pilleyre, S. Sanzelle, and M.S. Akselrod. "Gamma and Enclosure Dosimetry for TL/ESR Dating with the New A12O3:C TL Dosimeter." Proceedings of the 7th Int. Seminar on TL and ESR Dating, Krems, Austria, July 1993. Radiat. Meas., 23(2/3) pp.501-505 (1994).

2. M.S. Akselrod, A.L. Odegov, and J.S. Durham. "Aluminum Oxide Exoelectron Dosimetry." Proceedings of the Workshop "Individual Monitoring of Ionizing Radiation", Villigen, Switzerland, May 1993. Radiat. Prot. Dosim. 54(3/4) pp. 353-356 (1994).

3. W.W.S. McKeever, M.S. Akselrod and B.G. Markey. "Pulsed Optically Stimulated Luminescence Dosimetry Using $\alpha-\mathrm{Al}_{2} \mathrm{O}_{3}$ :C.” Radiat. Prot. Dosim. 65 267-272 (1996).

4. S.W.S. McKeever. Optically Stimulated Luminescence Dosimetry. SPIE, 3534, 531-541 (1999).

5. M.S. Akselrod, V.S. Kortov, and E.A. Gorelova. "Preparation and properties of $\mathrm{Al}_{2} \mathrm{O}_{3}:$ C." The 10th International Conference on Solid State Dosimetry, Washington, D.C., USA, Radiat. Prot. Dosim. 47(1/4), pp. 159-164 (1993).

6. G.F. Knoll. "Radiation Detection and Measurement." 2nd Edition, John Wiley and Sons, 1989.

7. J.S. Durham. "VARSKIN Mod 2 and SADDE Mod 2: Computer Codes for Assessing Skin Dose from Skin Contamination." NUREG/CR-5873 (1992). 